\title{
Effects of exposure to literary narrative fiction
}

\section{From book smart to street smart?}

\author{
Hannah N. M. De Mulder ${ }^{1}$, Frank Hakemulder ${ }^{2}$, \\ Rianne van den Berghe ${ }^{1}$, Fayette Klaassen ${ }^{3}$ and \\ Jos J. A. van Berkum ${ }^{1}$ \\ ${ }^{1}$ UiL OTS, Utrecht University, The Netherlands / ${ }^{2}$ Department of Media and \\ Culture, Utrecht University, The Netherlands / ${ }^{3}$ Department of Methodology \\ and Statistics, Utrecht University, The Netherlands
}

Literary narrative fiction may be particularly effective in enhancing Theory of Mind (ToM), as it requires readers to contemplate author and character intentions in filling the literary 'gaps' that have been suggested to characterise this fiction type. The current study investigates direct and cumulative effects of reading literature on ToM using confirmatory Bayesian analyses. Direct effects were assessed by comparing the ToM skills of participants who read texts that were manipulated to differ in the amount of gap filling they required. Cumulative effects were assessed by considering the relationship between lifetime literary fiction exposure and ToM. Results showed no evidence for direct effects of reading literature on ToM. However, lifetime literary fiction exposure was associated with higher ToM, particularly cognitive ToM. Although reading a specific piece of literary fiction may thus not have immediately measurable effects on ToM, lifetime exposure to this fiction type is associated with more advanced ToM.

Keywords: literary narrative fiction, Theory of Mind, literary gaps, literariness, author recognition test, Bayesian analyses

\section{Narrative fiction and understanding others' mental states}

On the morning the last Lisbon daughter took her turn at suicide - it was Mary this time, and sleeping pills, like Therese - the two paramedics arrived at the house knowing exactly where the knife drawer was, and the gas oven, and the beam in the basement from which it was possible to tie a rope.

(p. 1; Eugenides, 1993) 
The quote above is the first sentence of Eugenides' novel The Virgin Suicides and we are immediately sucked in: Who are Mary and Therese? Who are these other daughters who presumably died by stabbing, gassing and hanging themselves? And why on earth would multiple daughters in one family all commit suicide? This example illustrates a hallmark of narrative fiction: It is about autonomous intentional agents and their (inter)actions. If we are to understand the story, we have to try to make sense of the characters' social interactions, that is, we must engage in advanced social-cognitive processing (Mar \& Oatley, 2008; Zunshine, 2006). Social-cognitive processing is thus necessary in order to be able to appreciate narrative fiction (Barnes, 2012), but various researchers have suggested that this link also works the other way round: Reading narrative fiction might actually enhance our ability to engage in social-cognitive processing (Mar \& Oatley, 2008; Oatley, 1999a, 1999b; Oatley \& Mar, 2005; Sugiyama, 2001; see Mumper \& Gerrig, 2016 for a meta-analysis). The idea is that narratives give us unique insights into the mental lives of the characters that populate the story world. Furthermore, narratives provide us with the opportunity to live through the social situations that the characters in the narrative go through as if we were there experiencing them ourselves.

Reading fictional narratives is thought to enhance this experience further. The fiction reader knows that there are no moral obligations to help anyone in the real world and that there is no risk of experiencing any negative real life social consequences. This knowledge likely enables the reader to relax her defences and freely indulge in thoughts and feelings that may be triggered by the narrative (Hakemulder, 2000; Keen, 2007; Koopman, 2016a; Koopman \& Hakemulder, 2015). In this sense, then, our ability to understand others' mental states, our Theory of Mind (ToM) skills, may be deepened by reading narrative fiction.

In line with this idea, recent correlational studies have provided evidence that there is a positive relationship between cumulative exposure to narrative fiction across the lifetime and ToM in adults (Djikic, Oatley, \& Moldoveanu, 2013; Fong, Mullin, \& Mar, 2013; Mar, Oatley, Hirsh, de la Paz, \& Peterson, 2006; Mar, Oatley, \& Peterson, 2009; Panero et al., 2016; Stansfield \& Bunce, 2014). Similar findings have also been reported for children (see for instance Adrian, Clemente, Villanueva, \& Rieffe, 2005; Aram \& Aviram, 2009; Gamannossi \& Pinto, 2014; Ratner \& Olver, 1998). Whilst these correlational studies cannot be used to determine what the causal direction of the relationship is, various intervention studies have suggested that exposure to narrative fiction improves mental state understanding. For instance, reading a work of narrative fiction (as compared to reading a non-fiction text) was found to increase the self-reported tendency to take others' psychological viewpoint (at least for those low in the personality trait openness, see Djikic et al., 2013). Furthermore, various studies have demonstrated 
that performance on objective measures of mental state understanding (i.e., measures that assess ToM ability directly instead of relying on self-report) are also enhanced after exposure to narrative fiction as compared to exposure to non-fiction (Black \& Barnes, 2015; Kidd \& Castano, 2013; Kidd, Ongis, \& Castano, 2016; Pino \& Mazza, 2016).

\section{What are the 'active ingredients' of narrative fiction that enhance ToM?}

Previous research thus suggests that exposure to narrative fiction is beneficial for ToM. What is not clear, however, is what exactly the ToM-enhancing active ingredients' in narrative fiction might be. In their study, Fong et al. (2013) suggest that specific kinds of narrative fiction may be more effective than others in enhancing ToM. They investigated the relationship between exposure to various different narrative fiction genres (Domestic Fiction, Romance, Science-Fiction/Fantasy and Suspense/Thriller) and ToM task performance. Although the genres of Domestic Fiction, Romance and Suspense/Thriller were all related to better ToM scores (and overall exposure to fiction was also positively related to ToM), only exposure to Romance was still significantly correlated with ToM scores once relevant control variables (e.g., age, gender and exposure to non-fiction) were taken into account. Potentially, then, the fact that Romance fiction focuses so clearly on interpersonal relationships may stimulate its readers to ponder on social interaction more generally and thereby come to a greater understanding of other people's mental states. Although this study suggests that specific types of narrative fiction may be more clearly associated with ToM enhancement than others, a limitation of this work is that it is correlational in nature. It is thus possible that those who already have a better developed ToM prefer to read Romance fiction, instead of exposure to Romance fiction being responsible for the ToM enhancement.

Kidd and Castano (2013) also investigate the possibility that specific kinds of narrative fiction may be more effective than others in enhancing ToM. However, instead of contrasting different kinds of genre fiction (as Fong et al., 2013, did), they considered whether the literariness of a text could be linked to ToM enhancement. In their intervention study, Kidd and Castano (2013) assessed the ToM abilities of groups of participants who had either read literary narrative fiction, non-literary narrative fiction (popular fiction), expository non-fiction or nothing immediately prior to a ToM assessment. The results suggest that literary texts directly enhance ToM ability, whereas non-literary texts and expository non-fiction texts do not. These results were replicated (and shown to hold for a new set of literary and popular texts) in Kidd et al. (2016). Furthermore, a recent conceptual replication of this study by Pino and Mazza (2016) found similar results and thus also suggests 
that the literariness of the text is relevant in providing the reader with direct ToM gains. A correlational study by Kidd and Castano (2016) similarly demonstrates that exposure to literary narrative fiction over the lifetime is associated with higher ToM scores, whereas this was not the case for exposure to popular narrative fiction. However, it should be noted that these findings are debated in the literature. They are in contrast with the finding by Fong et al. (2013) that Romance fiction is positively correlated with ToM (given that Romance is not generally considered to be an instantiation of literary fiction). Furthermore, it is also not entirely clear to what extent these findings can be replicated, as there are various intervention studies that do not find a special relationship between exposure to literary narrative fiction and ToM. For instance, both Panero et al. (2016) and Dijkstra et al. (2015) did not find direct ToM enhancement for those participants who had read literary narrative fiction as compared to readers of other text types. Dijkstra et al. (2015) focused on the comparison between literary vs. non-literary narrative fiction and did not find any ToM differences. Panero et al. (2016) compared literary texts with both non-literary narrative fiction and non-fiction and similarly did not find any ToM differences between readers in the various conditions (although Kidd \& Castano, 2017, debate the validity of these conclusions in a commentary on the paper by Panero et al., 2016, and provide a reanalysis of the data that suggests that the Panero et al., 2016, findings are in fact in line with the results of Kidd and Castano, 2013).

There is thus debate in the literature on whether exposure to literary narrative fiction leads to direct ToM gains in the reader. But if we assume for the moment that literariness is indeed related to readers' ability to understand others' mental states, this raises the question why specifically literary narrative fiction might be more effective than other types of narrative fiction in enhancing our understanding of others. Potentially, literary narrative fiction provides the reader with a particularly rigorous social-interaction training, as this type of text requires deep psychological processing of authors' intentions and the characters' subjective experiences in order for full understanding to be achieved. Furthermore, literary texts tend to be more ambiguous than expository or non-literary narrative texts (see Koopman \& Hakemulder, 2015). In contrast, non-literary narrative fiction is considered to provide a more internally consistent and predictable portrayal of the context and characters (see Gerrig \& Rapp, 2004; Van Peer, 1986) and thus might not provide the reader with a 'ToM workout' that is rigorous enough to have immediately measurable effects (or, indeed, any effects at all). It is likely, then, that reading literary narrative fiction requires more profound psychological 'work' on the part of the reader as compared to non-literary narrative fiction and thus enhances ToM, both directly after exposure and as a cumulative effect of exposure over the lifetime (see also Kidd \& Castano, 2016, for discussion of this issue). 
That this interpretation of previous findings may be correct is supported by a study conducted by Peskin and Astington (2004) on the effects of narrative fiction exposure on the ToM abilities of young children. Children who were read a book that portrayed many situations in which an understanding of others' mental states was relevant, but that did not make these mental states explicit in the text itself, subsequently did better on measures of ToM than those who were read a book with the same storyline, but with rich mental state language. Likely then, children who were not exposed to explicit mental state language in the text had to work harder in order to understand the storyline and hence came to a deeper understanding of others' mental states than those who had received more support from the text itself. Having to engage in deep cognitive processing to be able to understand a given story character's mental states thus seems to be more beneficial in developing ToM than being provided with the content of others' mental states explicitly.

This process may not only apply to children, but to adults as well, as is suggested by the work of Kidd and Castano (2016). In this study it was found that literary texts contain more markers of reflective function than genre fiction texts. This characteristic of literary texts was found to mediate the effect of literary fiction on ToM performance. In line with the findings reported by Peskin and Astington (2004), these markers of reflective function do not reduce to the presence of mental state terms in a text, but instead relate to how mental states are discussed (e.g., although I was angry, now I am sad receives a relatively low reflective function rating, as the speaker only reports his emotions at different times, an utterance like $I$ felt really angry and then it changed to sadness receives a much higher rating as the speaker demonstrates an awareness of how their emotional response to something transformed over time). Indeed, further analyses reported in Kidd and Castano (2016) demonstrated that there was no difference between literary and genre fiction texts regarding the presence of words related to social and cognitive processes and these variables were not found to mediate the relationship between text type and ToM scores. There is thus some suggestion in the literature that the level of psychological 'work' that a reader has to engage in, which is typically higher in literary narrative fiction than popular fiction, may be important in determining whether or not a text will enhance ToM both immediately after reading and after extended exposure.

The current study aims to investigate whether it is indeed the case that exposure to literary narrative fiction, given its potential as a particularly rigorous ToM workout, enhances ToM in adults. This issue will be considered at the direct and the cumulative level, investigating both how reading specific pieces of literary narrative fiction affects ToM (direct effect) and how exposure to this type of narrative fiction over the lifetime relates to ToM skills (cumulative effect). 


\section{Literary narrative fiction and ToM: The relevance of 'gaps'}

In investigating whether there are direct effects of literary narrative fiction on ToM skills, the current study focusses on the presence of literary 'gaps' in a text (Iser, 1978, 1988). In Iser's conceptualization of information gaps it is assumed that these are characteristic of literature. In literary texts, we find gaps that have to be (more or less) filled in order to allow for a full (or fuller) comprehension of the narrative by the 'ideal' or implied reader. The text invites, or appeals to, the reader to be creatively involved in filling in these gaps (cf. Iser, 1975). Time lapses, discontinued sub-plots and open endings are examples of narrative devices that may give rise to literary gaps as they stimulate readers to fantasize about what happened in the meantime and to postulate character behaviour on the basis of what they already know about the character. Similarly, texts that provide conflicting perspectives of two or more narrating characters also provide many gaps to be filled (regarding, for instance, the narrators' morality and reliability in their telling of events). Another example of gap filling relates to the extent to which the social situation that readers are introduced to is clarified in the text (cf. Van Peer, 1989). Readers in popular fiction are typically informed directly from the start who is who (e.g., by referring to characters by naming them when introduced), which thoughts and utterances are to be attributed to which character and explicitly defining what the relationship between the characters is. However, content analysis of a corpus of popular and literary narratives (Van Peer, 1989) suggests that in literary texts such aspects are often left 'open' (as the opening sentence of the literary novel by Eugenides at the beginning of this article illustrates). It is this latter type of gap filling that will be manipulated in the current study, as gaps of this nature most clearly require readers to contemplate characters' thoughts and social relationships in order to be able to make sense of the narrative. Following Kidd and Castano (2013), who suggest that the presence of literary gaps in the narrative structure may be important in explaining the relationship between literature and ToM, our assumption is that exposure to a text that is rich in these kinds of gaps will have a more pronounced direct effect on ToM than texts with fewer (or no) gaps. In order to investigate whether this is indeed the case, in the current study readers were provided with a literary narrative fiction text (one of the texts used in Kidd \& Castano, 2013) or a non-fiction text. The literary text was either read in its original form (for maximal levels of required gap-filling) or in one of two adapted forms in which the amount of psychological work that was required was either somewhat or considerably reduced. For instance, readers of the adapted texts were immediately informed of the identity of one of the central figures in the story, whereas the original text does not make this information clear until much later in the text (see the Method section for more information on the 
text manipulations and further examples). A final group of readers received an expository non-fiction text, such that effects of reading a text for which literary gap filling was not required could also be assessed. After exposure to one of these four texts, participants were given various ToM measures, such that ToM differences between the groups could be determined.

Aside from assessing whether reading a specific piece of literary narrative fiction would have a direct effect on ToM, the current study also investigated whether exposure to literary narrative fiction over the lifetime would have a cumulative effect on ToM. Given that previous correlational studies have found exposure to narrative fiction in general over the readers' lifetime to be associated with ToM (e.g., Panero et al., 2016) and that literary narrative fiction in particular may be linked to higher ToM (e.g., Kidd \& Castano, 2013, 2016; Kidd et al., 2016), our assumption was that more exposure to literary narrative fiction over the lifetime would result in more advanced ToM skills. In order to investigate this question participants were given a test that assessed their exposure to both literary and popular narrative fiction (based on author recognition, see Method section). In this way, the current study can assess the effects of literariness on ToM ability both in a direct sense (depending on what particular text a participant has been exposed to) and cumulatively (depending on the extent of lifetime literary narrative fiction exposure).

This design thus enables us to contribute to current knowledge on the relationship between narrative fiction and ToM in various ways. In the first place, the study will provide additional experimental evidence for the presence or absence of direct effects of reading literary narrative fiction on ToM. Although some previous studies have found evidence for this relationship (Kidd \& Castano, 2013; Kidd et al., 2016; Pino \& Mazza, 2016), other studies have not (Dijkstra et al., 2015; Panero et al., 2016). Our study aims to add to this debate not only by comparing the ToM skills of readers of literary narrative fiction vs. other types of texts (as previous studies have done), but also by focusing on one particular characteristic of literary narrative fiction, the presence of literary gaps, that is likely to be an 'active ingredient' in enabling direct ToM gains. Secondly, the current study investigates whether cumulative ToM gains are present for those who have higher lifetime exposure to literary narrative fiction. Whereas previous studies have often focused on cumulative ToM effects related to general exposure to narrative fiction (e.g., Djikic et al., 2013; Mar et al., 2006, 2009; Panero et al., 2016), the current study is one of the few studies (together with Kidd \& Castano, 2016) that assess whether this relationship might also hold for, or even be specific to, literary narrative fiction. 


\section{Competing hypotheses regarding effects of narrative fiction exposure on ToM}

The current study employs a confirmatory Bayesian approach of data analysis, which entails that prior to data analysis various competing hypotheses regarding the possible outcomes of the study are formulated in a very precise manner. Which specific competing hypotheses are chosen is based on the outcomes of previous studies and on current theorising on the matter (Hoijtink, 2012). The formulated hypotheses are then evaluated against the data in order to determine which hypothesis receives the most support in the current dataset. The Data Analysis section provides more information on this analysis approach and a more precise formalisation of the hypotheses, but an overview of the hypotheses and the basic assumptions behind them are detailed here.

To investigate direct effects of exposure to (literary) narrative fiction on ToM ability four competing hypotheses were formulated. Our first hypothesis is based on Kidd and Castano's (2013) results and states that the more literary the text that the reader has been exposed to, the greater its effect will be on ToM ability immediately after exposure. Reading the original literary text will thus be associated with the highest ToM scores, followed by the two adaptations (in order of literariness) and the expository non-fiction text. Our second evaluated hypothesis is based on a more extreme interpretation of Kidd and Castano's findings. Given that only literary texts were found to enhance ToM ability in their study, it could also be the case that any manipulation that decreases a text's literariness immediately 'devalues' it to such an extent that it no longer qualifies as a literary text and thus no longer has any immediately measurable effects on ToM ability. If this is indeed the case, then the highest ToM scores will be obtained by the readers who were exposed to the original version of the literary text, but there will be no difference in ToM scores for the readers who were exposed to any of the other texts. Our third hypothesis is based on the body of literature that has not made a specific distinction between different types of narrative fiction, but that suggests that narrative fiction in general enhances ToM more than non-fiction (e.g., Mar et al., 2006, 2009). Following this hypothesis, we would expect to see higher ToM scores for the readers of the narrative fiction texts as compared to the expository non-fiction text, but no differences between scores depending on the literariness of the narrative fiction text that had been read. The final hypothesis that was formulated is based on the results of Panero et al. (2016) and states that reading literary narrative fiction is not associated with direct ToM gains, whatever the level of literariness of the text. If this is the case, we would not expect to see any differences in ToM between the various reader groups in the study. 
To investigate cumulative effects of exposure to (literary) narrative fiction on ToM ability, the current study also formulated hypotheses regarding effects of lifetime exposure to narrative fiction, both in general and as regards literary and popular narrative fiction in particular. For general exposure to narrative fiction (i.e., exposure to literary and popular narrative fiction combined), three competing hypotheses were formulated: Narrative fiction exposure could be positively, negatively or not related to ToM ability. We expected there to be a positive relationship between the two given results of previous studies (Djikic et al., 2013; Mar et al., 2006, 2009; Panero et al., 2016). The two logical opposites of this hypothesis were investigated in order to determine how well this hypothesis would fare against them.

The final three competing hypotheses were formulated with regards to exposure to literary narrative fiction over the lifetime. If literary narrative fiction is of primary importance in enhancing ToM ability (as suggested by Kidd \& Castano, 2013, 2016), we would expect to see scores on lifetime literary narrative fiction exposure to be positively correlated with ToM and more strongly so than lifetime exposure to popular narrative fiction. To determine the strength of this hypothesis, we compared this hypothesis to two clear counterhypotheses. The first of these two counterhypotheses evaluated the possibility that lifetime literary and popular fiction exposure would not differ in their relation to ToM ability (in line with what would be expected if the outcomes of the intervention studies by Dijkstra et al., 2015, and Panero et al., 2016, also hold for lifetime exposure). The second, more extreme, counterhypothesis evaluated the possibility that there would be no relation between lifetime literary exposure and ToM at all (in direct contrast to the claims by Kidd \& Castano, 2013, 2016).

\section{Method}

\section{Participants}

121 participants (90 women), recruited from a large pool of participants at the University of Utrecht in the Netherlands, took part in this study in exchange for a small fee (5 euros). Participants were non-dyslexic native speakers of Dutch between 18 and 30 years old $(M=21 ; 8, S D=2.9)$. By far the most were students, but some participants indicated having other occupations. 


\section{Materials}

Four different texts were used (full translated versions of the texts can be found in the Appendix): An original literary text, two adaptations of this same text (differing in the amount of gap-filling they required) and an expository non-fiction text. The literary text that was used was the short story $A$ chameleon by Chekhov (1884/1978). This text was chosen as it was also part of the study by Kidd and Castano (2013) and it had a Dutch translation available (Chekhov, 1884/2014). The material was manipulated such that it would be possible to assess to what extent the presence of literary gaps would be associated with ToM gains. A characteristic of the story A chameleon is that it remains implicit which character is responsible for the many instances of direct discourse that are present in the text. Figuring out who said what is thus a crucial element of the original version of the story. Furthermore, the story contains various instances of oblique reference (i.e., it is not immediately clear to whom/what particular pronouns refer) and the social relations between characters are also not always clarified in the text (see Table 1 for examples; changes are rendered in boldface). Our assumption was thus that the original text would place a greater burden on readers to fill these literary gaps and thereby provide them with a better ToM workout than manipulated versions of this text in which some or most of these gaps had been filled.

The three literary text conditions consisted of the story A chameleon in its full original form (consisting of 1216 words), in a version in which the text had been manipulated such that only the prominent gaps in the story were filled (1233 words, limited manipulation version) or in a version in which many more of the gaps were filled (1214 words, extensive manipulation version). In the limited manipulation version instances of direct discourse were provided with sources and initially oblique references were clarified immediately. The extensive manipulation version contained all the changes present in the limited manipulation version as well as further changes that were intended to make it even easier for readers to understand the social situation of the story (and hence character motives and emotions) by removing all possible obstacles to this understanding. In the first place, the story was adapted such that it would fit in the modern Dutch context that was familiar to the participants instead of the older Russian context of the original. This entailed that all Russian names were changed to Dutch names, and that Dutch professions, authority figures and prototypical hierarchical orders were used instead of Russian ones. We assumed that these 'translations' to the more familiar context of the readers would entail that they would have to put less effort into understanding who was who and how everyone was related to each other. Secondly, parts of the text were deleted from the story if we thought that they may give rise to literary gap-filling without being directly relevant for plot comprehension. To 
give an example: At the beginning of the story a parcel is prominently introduced, but it plays no role in the rest of the story. As readers might be inclined to spend psychological work on guessing what the author's intention might have been in introducing this parcel, this information was deleted from the text. By manipulating the text in these ways, we assumed that readers of the extensive manipulation version would be provided with fewer opportunities to engage in psychological 'work' than readers of the original text and the limited manipulation version.

Table 1. Examples of the original text and the two manipulated versions

\begin{tabular}{|c|c|}
\hline Text type & Text example \\
\hline Original & $\begin{array}{l}\text { "Shut your mouth!" } \\
\text { "No, that's not the General's dog," says the policeman, with pro- } \\
\text { found conviction, "the General hasn't got ones like that. His are } \\
\text { mostly setters." } \\
\text { "Do you know that for a fact?" }\end{array}$ \\
\hline Limited manipulation & $\begin{array}{l}\text { "Shut your mouth!" Otsjoemelov orders. } \\
\text { "No, that's not the General's dog," says policeman Jeldyrin with } \\
\text { profound conviction, "the General hasn't got ones like that. His are } \\
\text { mostly setters." } \\
\text { "Do you know that for a fact?" Otsjoemelov asks. }\end{array}$ \\
\hline Extensive manipulation & $\begin{array}{l}\text { "Shut your mouth!" Jansen orders. } \\
\text { "No, that's not the chief commissioner's dog" says policeman De } \\
\text { Vries with profound conviction, "The chief commissioner hasn't } \\
\text { got ones like that. His are mostly setters." } \\
\text { "Do you know that for a fact?" Jansen asks. }\end{array}$ \\
\hline
\end{tabular}

Note. Differences as compared to original text are rendered in bold face.

The expository non-fiction text that was used was a slightly adapted version of an article from the Dutch edition of the National Geographic magazine (Van Beem, 2015). This article provided information on the biology and habitat of chameleons. Although the original length of the expository non-fiction text was close to that of the literary fiction text, the adapted version was somewhat shorter ( 985 words), as the more narrative and emotional aspects of the text were filtered out such that the contrast between the two text types was as great as possible.

\section{Measures}

\section{Lifetime fiction exposure}

Lifetime exposure to fiction was assessed using an Author Recognition Test (ART, Stanovich \& West, 1989) in which participants have to indicate which author names they recognise from a large list of names. Although the ART does not assess 
lifetime fiction exposure in a direct sense (by asking respondents directly about the frequency and duration of their fiction reading habits), this measure is commonly interpreted as a general measure for print exposure. It has been found to be a good predictor for other measures related to print exposure such as reading skills (Mol \& Bus, 2011) and exposure to fiction (West, Stanovich, \& Mitchell, 1993). Furthermore, this test has the added benefit that it does not run the risk of obtaining socially desirable responses in answering direct questions regarding reading frequency/duration. Attempts to assess general print exposure have sometimes included more than just the names of fiction authors (e.g., magazine titles, see West et al., 1993), but the current study employs a version of the ART created by Koopman (2015a, 2015b, 2016b) that focuses specifically on exposure to narrative fiction authors. Given this more targeted focus, we suggest that this version of the ART will be better capable of providing us with information on lifetime exposure to narrative fiction than using a more general ART. Furthermore, Koopman (2016a) found that avid readers of literature scored significantly higher on her ART than a control group did. Moreover, it is important for the present purpose that this ART has been specifically designed with Dutch participants in mind, and that it allows for a distinction between recognizing literary and popular authors. (Authors classified as literary had received critical acclaim and nominations for literary prizes; authors in the popular category had written best-selling novels that are relatively easy to read.) Although we acknowledge that we have no direct validation of the relationship between recognition of literary vs. popular author names and actual exposure to literary vs. popular narrative fiction, we note that the ART as a measurement tool has been found to relate to actual narrative fiction exposure and that previous studies that apply factor analysis to the ART find a two-factor solution that can be broken down into a literary and a popular fiction factor (see Kidd \& Castano, 2016; Moore \& Gordon, 2015). We thus consider it to be a reasonable assumption that the version of the ART that we use will be informative regarding exposure to literary and popular narrative fiction in our Dutch sample.

Participants were given a list consisting of 42 names. Thirty of these names belonged to actual authors, 12 of the names were foils. Of the 30 author names, 15 belonged to literary fiction writers and 15 to popular fiction writers; in both categories national (i.e., Dutch) and international author names were present. Participants could thus score a maximum of 30 points in total for the ART (reflecting general exposure to narrative fiction); the literary and popular subcomponents of the ART (reflecting exposure to literary and popular narrative fiction) were each worth 15 points. Participants were told that they did not have to have read the work of the author themselves in order to check the name, they just had 
to be sure that the name belonged to an actual author. Guessing was discouraged by informing participants that there were also made-up names in the list.

\section{ToM}

Dutch versions of two different measures of ToM were employed: The Reading the Mind in the Eyes Task (RMET, Baron-Cohen, Wheelwright, Hill, Raste, \& Plumb, 2001) and the Yoni task (Shamay-Tsoory \& Aharon-Peretz, 2007). We used these tasks as previous work by Kidd and Castano (2013) has shown that performance on both of these tasks is enhanced after reading literary narrative fiction. In the RMET task, participants are shown the eye region of a series of 36 different faces and are required to choose from four possibilities (e.g., irritated, sarcastic, worried or friendly) which option best conveys the mental state that is being signalled. Although some of the response options refer to an understanding of cognitive mental states (e.g., contemplative, thoughtful), by far the most of the response options refer to affective mental states (e.g., hostile, anxious, affectionate). The RMET thus primarily measures participants' ability to attribute affective mental states to others (i.e., it assesses knowledge about others' feelings) and thus is primarily a test of affective ToM.

The Yoni task assesses ToM in a broader sense than the RMET, as understanding of both cognitive and affective mental states is assessed in equal measure. Furthermore, understanding of these two types of mental states is assessed at both the first and second order level. In each trial, participants see a cartoon face called Yoni in the centre of the screen, a picture in each corner of the screen and a sentence at the top of the screen. This sentence expresses Yoni's cognitive or affective mental state in relation to one of the four other pictures on the screen. The participant's goal is to determine to which of the four pictures the sentence refers, given the verbal and visual clues to Yoni's mental state that are present in the stimulus. In the assessment of cognitive mental states ( 25 trials in total with 13 first order trials and 12 second order trials), ${ }^{1}$ the facial expressions of all characters in the stimulus and the verbal cue are emotionally neutral. In the first order cognitive trials, the four pictures in the corners of the screen are all of objects and the participant has to use Yoni's eye gaze direction in order to determine which of these objects Yoni is thinking about (example stimulus sentence: Yoni is thinking of...). In the second order cognitive trials, the four pictures each represent another character together with an object. For these trials, the participant has to demonstrate understanding of Yoni's beliefs about these other characters' beliefs and desires (e.g.,: Yoni is thinking of the toy that ...wants). Cognitive trials thus assess participants'

1. Unfortunately, experimenter error entailed that one first order cognitive trial too many was included. The original version of the task thus has 12 first order cognition trials instead of 13 . 
understanding of Yoni's thoughts (in the first order trials) and Yoni's thoughts as related to others' thoughts/desires (in the second order trials) in an emotionally neutral context. In the affective trials ( 24 in total, with 12 first order and 12 second order trials), the facial expressions of the characters and the verbal cue are affective in nature (either positive or negative). In the first order trials, participants have to use this affective information to determine Yoni's feelings regarding a particular object (e.g.,: Yoni loves ...). In the second order affective trials, again, the four pictures consist of other characters together with objects and the participant has to demonstrate an understanding of Yoni's emotions in regard to the other characters' emotions in order to score points on the task (e.g.,: Yoni loves the toy that ... loves). Affective trials thus assess participants' understanding of Yoni's feelings (in the first order trials) and Yoni's feelings as related to others' feelings (in the second order trials) in an emotionally loaded context. These 49 trials, requiring first and second order understanding of cognitive and affective mental states, are the core component of the Yoni task and were the focus of the analysis in the current study. In addition to these 49 core items, participants also received 49 additional trials that were not analysed for this study. ${ }^{2}$ These trials consisted of items assessing understanding of Yoni's physical states (e.g., Yoni is close to...) and items that assessed understanding of emotions relating to the fortunes of others such as envy and gloating (e.g., Yoni envies...; see Shamay-Tsoory, Tibi-Elhanany, \& Aharon-Peretz, 2007 , for more information on these conditions).

\section{Procedure}

Participants were tested individually in a testing booth with each session lasting between 30-45 minutes. Upon arrival, each participant read and signed an informed consent form that gave them general information about the study. On obtaining consent, participants were given general instructions about the experimental procedure, and then started the experimental session by reading the text that they had been assigned to (the text was provided to them on paper). Participants were encouraged to take as much time as they wanted to read the text and to reread it if necessary. After having read the text, participants were given the RMET, the Yoni task and the ART to complete. Finally, the participants received a questionnaire

2. It should be noted that the outcomes for these additional trials were not inspected at any point in the preparation of this manuscript. In keeping with the Bayesian analysis approach, only those analyses were conducted for which hypotheses had been specified prior to data analysis (deviations from this approach are clearly marked as such in the Data Analysis section). The decision to include only the core Yoni trials in this study was thus based only on the fact that these were the trials used in previous related research in which the Yoni task was applied and on no other considerations. 
that asked them to report on their experience during the experiment as a whole and whilst reading the text they had been assigned to. This questionnaire also served to ensure that participants had paid sufficient attention to the text, as they were required to answer three multiple choice text comprehension questions. If at least two out of these three questions were not answered correctly, the participant's data was removed from the analysis. Participants were also asked whether they had read the text (or a text that was similar to the text they had read) before, such that participants who were already familiar with the texts in the study could be removed from analysis. After each task, the experiment leader entered the booth to start the next task and to give instructions tailored to the upcoming task. After completing the final questionnaire, the participant was paid and debriefed.

\section{Data analysis}

The data analysis approach employed by this study relied on informative hypotheses and Bayesian model selection (Hoijtink, 2012) using the software BIEMS (Mulder, Hoijtink, \& de Leeuw, 2012). A crucial aspect of this approach is that, prior to observation of the data, various competing hypotheses are specified based on information obtained from previous research and current theorising (Kluytmans, van de Schoot, Mulder, \& Hoijtink, 2012; van de Schoot et al., 2011; van de Schoot et al., 2014). These specific hypotheses are then compared against each other (and not against the null hypothesis as is the case in classical frequentist hypothesis testing, see Harlow, Mulaik, \& Steiger, 1997). The Posterior Model Probability (PMP) that is associated with each hypothesis is then used as an indication of the amount of evidence that there is in the data for each particular hypothesis over other evaluated hypotheses (see Results section more information on this concept).

Due to the fact that only pre-specified hypotheses are assessed, use of smaller sample sizes is not generally problematic in this approach (whereas this can be a cause for concern in classical hypothesis testing). That is, under a Bayesian approach, what is being evaluated is a very specific set of questions: Is the data structured as specified under Hypothesis X, Y or Z? Depending on the PMP values that are associated with each hypothesis, one hypothesis may clearly be more supported than the others, or there may be no clear 'winner', in which case the conclusion can be drawn that none of the specified hypotheses is any better than the others in accounting for the data. The only way in which sample size is of influence is that larger sample sizes may lead to stronger support for one of the hypotheses (but support can still be computed for smaller sample sizes). This is in contrast with classical hypothesis testing in which the underlying question is much broader: Are the values associated with the variables of interest the same or do they differ in any of the multitude of possible ways in which they could potentially differ from each 
other? In this case, a small sample size may incorrectly lead to a non-rejection of the null hypothesis because the power is too low.

This confirmative approach thus allows for more precise testing of hypotheses even with relatively small sample sizes, does not rely on arbitrary cut-off points and reduces the chance of obtaining false positives and false negatives, and, as such, is the approach of choice for this study.

\section{Direct effects}

Four competing hypotheses relating to the effect of text literariness on ToM were devised (see also the Competing hypotheses regarding effects of narrative fiction exposure on ToM section). Hypothesis 1-DE (i.e., the first Hypothesis regarding Direct Effects) assumes that exposure to the original literary text will be associated with the greatest gains in ToM and that decreasing the amount of psychological work necessary will have a detrimental effect on these gains: ${ }^{3}$

Hypothesis 1-DE:

Original $>$ limited manipulation $>$ extensive manipulation $>$ non-fiction

Hypothesis 2-DE presents the more extreme version of Hypothesis 1-DE and states that only exposure to the original literary text will enhance ToM, whereas any decrease in literariness will no longer lead to ToM improvement:

Hypothesis 2-DE:

Original $>$ limited manipulation $=$ extensive manipulation $=$ non - fiction

Following Hypothesis 3-DE, exposure to any kind of narrative fiction text, be it manipulated or not, will have a favourable effect on ToM scores:

Hypothesis 3-DE:

Original $=$ limited manipulation $=$ extensive manipulation $>$ non-fiction

The final hypothesis, Hypothesis 4-DE, formalises the notion that exposure to (literary) narrative fiction texts is not related to ToM performance:

Hypothesis 4-DE:

Original $=$ limited manipulation $=$ extensive manipulation $=$ non - fiction

\section{Cumulative effects}

For the cumulative effects of exposure to general narrative fiction over the lifetime three competing hypotheses were formalised (see Figure 1 for a visualisation of

3. Note that separate analyses were run for the two different ToM measures, but the predictions are the same for both measures. 
the correlation procedure that is employed in these analyses). Hypothesis 1-CE (i.e., the first Hypothesis regarding Cumulative Effects) postulates that there is a positive correlation between exposure to narrative fiction and ToM. The other two hypotheses have been formulated such that they counter this notion: Hypothesis 2-CE states that there is a negative relationship and Hypothesis 3-CE claims that there is no relationship between narrative fiction exposure and ToM.
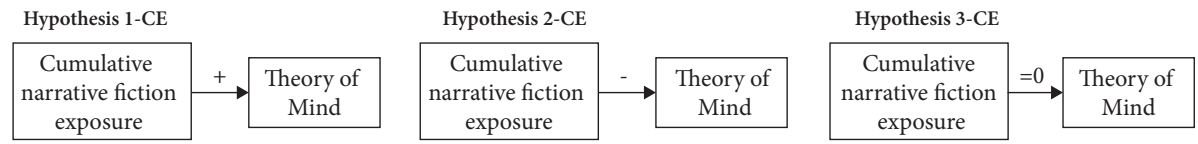

Figure 1. Hypotheses cumulative effects for general narrative fiction exposure on ToM. Note. + denotes a positive correlation, - a negative correlation and $=0$ denotes a lack of correlation between the dependent and independent variables.

In addition to these three hypotheses relating to effects of cumulative exposure to narrative fiction in a general sense, the final three hypotheses regarding cumulative effects considered effects of exposure to popular and literary narrative fiction over the lifetime (see Figure 2, for a visualisation of the regression procedure that is employed in these analyses). Hypothesis 4-CE predicts that exposure to literary fiction will be positively related to ToM (formalised as $ß 1>0$ with $ß 1$ denoting the standardised regression coefficient for literary narrative fiction exposure in relation to ToM) and more strongly related to ToM than exposure to popular narrative fiction (formalised as $ß 1>ß 2$, with $ß 2$ denoting the standardised regression coefficient for popular narrative fiction in relation to ToM). This hypothesis is contrasted with two hypotheses that go against this notion. Hypothesis 5-CE specified the claim that literary narrative fiction exposure does not deserve a special status, but instead that there is no difference between exposure to literary and popular narrative fiction in their relation to ToM (formalised as $ß 1=ß 2$ ). Finally, Hypothesis 6-CE states that exposure to literary narrative fiction is unrelated to ToM $(B 1=0)$.

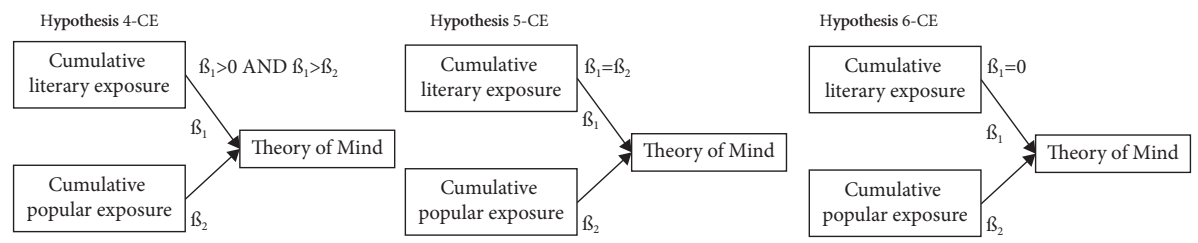

Figure 2. Hypotheses cumulative effects literary vs. popular narrative fiction on ToM. Note. $\beta_{1}$ and $\beta_{2}$ are standardised regression coefficients; $\beta_{1}$ denotes the relationship between exposure to literary narrative fiction and Theory of Mind; $\beta_{2}$ denotes the relationship between exposure to popular narrative fiction and Theory of Mind. 


\section{Results}

\section{Descriptive statistics and correlations}

Prior to data analysis, data from two participants was discarded. One of these two participants had taken an excessively long time to read the text (taking more than twice the time that the other participants needed on average) and complained of severe concentration problems during the experiment in the final questionnaire. The other discarded participant failed the exclusion criterion of answering at least two out of the three basic text comprehension questions correctly (as posed in the final questionnaire). ${ }^{4}$ All the analyses reported below are thus based on the remaining set of 119 participants (all between 18 and 30 years old; $M=21 ; 8$, $S D=2.9 ; 89$ women).

Table 2 provides the descriptive statistics of the scores on the ToM assessments and the ART, both overall and broken down per text condition. Note that the cells above the dashed border present the descriptive statistics that are relevant for the assessment of direct effects on ToM, while the cells below this border relate to the cumulative effects. The ART scores are broken down by text condition such that potential group differences in lifetime exposure to narrative fiction can be considered. Although the popular ART scores are very similar between groups, there are larger differences between groups for the ART literary scores (and thus also the ART overall scores). This potential confound will be dealt with in the analyses presented in the following sections.

It should be noted that only a very small number of foils was chosen in the ART $(M=0.24 ; S D=.58)$. By far the most of the participants $(81.5 \%)$ checked zero foils (95.8\% of participants checked zero or one foil) and no more than three foils were checked by any participant. Given that the number of foils checked was not part of our pre-specified hypotheses and this inspection of the data did not provide a clear motivation for us to take this variable into account in additional post-hoc analyses, we did not consider it in further analyses.

Table 3 provides the correlations between the ToM tasks and the lifetime exposure measures.

4. None of the participants indicated that they were already familiar with the texts that they had read, so none were excluded on this basis. 


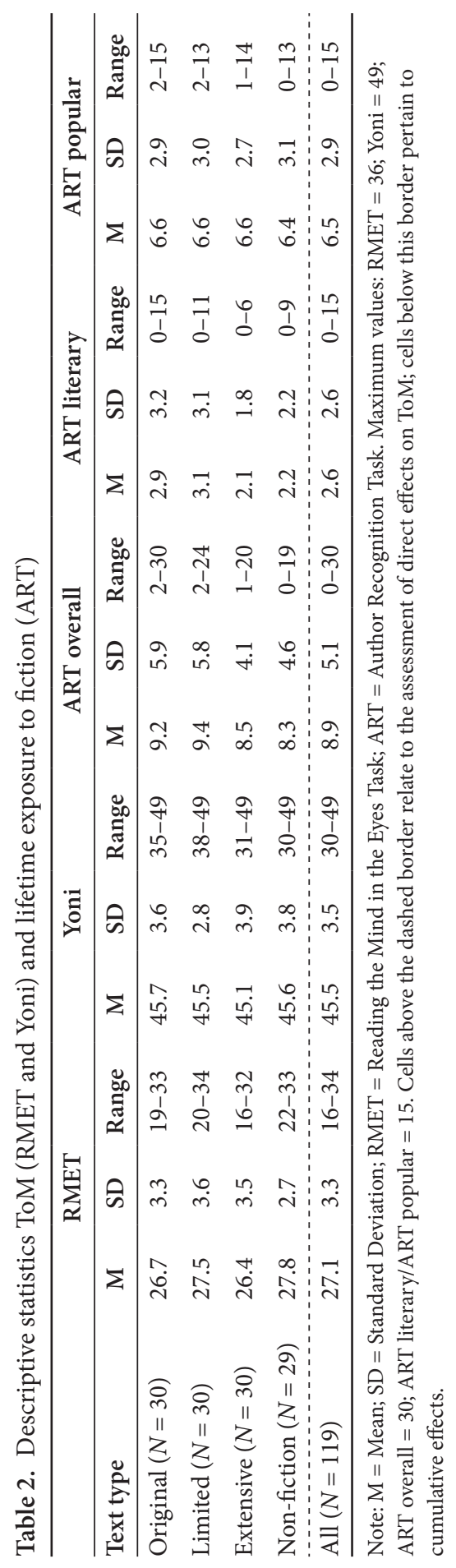


Table 3. Correlations between ToM (RMET and Yoni) and lifetime exposure to fiction (ART)

\begin{tabular}{lcccc}
\hline & RMET & Yoni & ART overall & ART literary \\
\hline Yoni & .26 & & & \\
ART overall & .03 & .12 & & \\
ART literary & .03 & .18 & .92 & .71 \\
ART popular & -.01 & .05 & .92 &. \\
\hline
\end{tabular}

Note. RMET $=$ Reading the Mind in the Eyes Task; ART = Author Recognition Task.

\section{Effects of text literariness: Direct effects}

In the interpretation of the results in the following sections the Posterior Model Probability (PMP) will be used to determine which of the tested hypotheses is most supported. ${ }^{5}$ The PMP gives the probability that a particular hypothesis is the most supported by the data given all the specific hypotheses that are evaluated, taking into account the complexity and the fit of the hypothesis. If a particular experimental hypothesis thus has a PMP of, for example, 0.64 , this entails that the probability is $64 \%$ that preferring this hypothesis over other evaluated hypotheses is the right choice. ${ }^{6}$ Importantly, there should be no rules regarding what constitutes a sufficient value. As Rosnow and Rosenthal (1989) already stated regarding the .05 rule to decide whether a p-value is significant: "Surely, God loves the .06 nearly as much as the .05 " (p. 1277). Any rule for the interpretation of the size of PMPs is subject to the same criticism. The results are thus summarised and reported in this section and their interpretation is reflected upon in the discussion section.

Table 4 provides PMPs for Hypothesis 1-4-DE in relation to performance on the RMET and Yoni task. The shaded cells represent the hypothesis with the highest PMP (i.e., the model that is most supported by the data). Aside from the PMP values of the specified hypotheses (i.e., Hypotheses 1-4-DE which consist of pre-specified constraints), Table 4 also provides PMP values for the unconstrained hypothesis. This hypothesis does not have any formulated constraints (it formalises the notion

5. For the unconstrained hypothesis a vague prior was used and the priors for the other hypotheses are derived from this vague prior via truncation. Discussion of this issue is very technical in nature and beyond the scope of this paper. However, the reader is referred to Mulder, Hoijtink and Klugkist (2009) and Mulder et al. $(2009,2012)$ for further discussion.

6. It should be noted that the level of uncertainty that is present in the data is reflected in these PMP values. That is, more uncertainty in the data leads to lower PMPs for the pre-specified hypotheses and makes it less likely that one hypothesis will clearly come out as the 'winner'. Giving an overview of the confidence intervals that are associated with the data thus does not provide any additional insight above and beyond the PMPs. 
something is going on, but I don't know what) and is generally considered in addition to the pre-specified hypotheses in order to get an indication of the quality of the pre-specified hypotheses (Hoijtink, 2012). If the unconstrained PMP value is high, this suggests that the constraints that have been specified are ill-chosen (because evidently they are not supported better by the data than a hypothesis that does not impose any constraints). As can be seen from this table and the other tables presenting the results, this is not a concern in the current study, as the most supported hypotheses have clearly higher PMPs than the unconstrained hypotheses.

Table 4. Direct effects of text condition on ToM (RMET and Yoni)

\begin{tabular}{lcc}
\hline Hypothesis & RMET PMP & Yoni PMP \\
\hline 1-DE: More literary $\rightarrow$ better ToM & 0.01 & 0.05 \\
2-DE: Original text $\rightarrow$ better ToM & 0.03 & 0.06 \\
3-DE: Any literature $\rightarrow$ better ToM & 0.01 & 0.03 \\
4-DE: No differences & 0.83 & 0.81 \\
Unconstrained & 0.11 & 0.04 \\
\hline
\end{tabular}

The results presented in Table 4 demonstrate that there is very little support in the data to suggest that reading narrative fiction of any type is associated with better performance on the ToM tasks. Indeed, the PMPs of Hypotheses 1-3-DE are very low, whereas Hypothesis 4-DE is very high both for the RMET and the Yoni task (the chance that Hypothesis 4 -DE is the right choice is $83 \%$ in relation to performance on the RMET task and $81 \%$ in relation to performance on the Yoni task). The descriptive statistics presented in Table 2 also underscore this conclusion: The differences in RMET and Yoni average scores between participants that had read different text types are minimal. Reading a specific text type thus does not seem to have any immediately measurable effects on RMET or Yoni performance.

It is important to clarify here what this outcome means given the Bayesian confirmative approach that we apply. Although on the face of it this finding represents a null effect, our approach allows us to quantify exactly what level of support there is in the data for this 'null' hypothesis. That is, there is an $83 \%$ chance that preferring this hypothesis over the other evaluated hypotheses is the right choice for the RMET analysis (and an $81 \%$ chance for the Yoni analysis). It is thus not the case that we can only conclude that we cannot reject the null hypothesis, but that we don't really know whether the participants in the various text conditions differ from each other or not (as would be the case in classical null hypothesis testing). Instead, the results of this analysis show very clear support in favour of the assumption that the participants in the various text conditions do not differ from each other in their ToM scores. 
Note, though, that the descriptive statistics presented in Table 2 suggest that there are differences between groups regarding the exposure to literary narrative fiction over the lifetime and, by consequence, in overall exposure to narrative fiction (i.e., ART literary scores, and thus also ART overall scores, are lower for the extensive manipulation and the non-fiction text groups than for the original and the limited manipulation text groups). As these differences may have influenced the results regarding the direct effects of reading different text types on ToM, posthoc analyses were run to investigate this issue. These analyses are identical to the ones reported above, but they also controlled for the ART literary scores. ${ }^{7}$ These analyses yielded essentially the same results as those presented above. That is, the specific PMP values of the models change if the ART scores are added to the analyses, but hypothesis 4-DE is still clearly the most supported by the data (see Table 5). There is thus no interaction between the text condition that participants were placed in and scores on the ART.

Table 5. Direct effects of text condition on ToM (RMET and Yoni) controlling for ART literary

\begin{tabular}{lcc}
\hline Hypothesis & RMET PMP & Yoni PMP \\
\hline 1-DE: More literary $\rightarrow$ better ToM & 0.03 & 0.12 \\
2-DE: Original text $\rightarrow$ better ToM & 0.07 & 0.13 \\
3-DE: Any literature $\rightarrow$ better ToM & 0.03 & 0.08 \\
4-DE: No differences & 0.63 & 0.58 \\
Unconstrained & 0.24 & 0.09 \\
\hline
\end{tabular}

\section{Cumulative effects: Narrative fiction and ToM over the lifetime}

Table 6 shows the results for the first three hypotheses regarding effects of lifetime exposure to general narrative fiction on ToM.

Table 6. Cumulative effects of general narrative fiction exposure on ToM (RMET and Yoni)

\begin{tabular}{lcc}
\hline Hypothesis & RMET PMP & Yoni PMP \\
\hline 1-CE: + relationship & 0.11 & 0.30 \\
2-CE: - relationship & 0.07 & 0.03 \\
3-CE: No relationship & 0.73 & 0.50 \\
Unconstrained & 0.09 & 0.17 \\
\hline
\end{tabular}

7. The same analyses were also run controlling for ART overall scores, but these differ only very minimally from the analyses provided in Table 5 , given that the differences lie in the ART literary scores. 
These results demonstrate that for both ToM tasks, there is the most support in the data for the claim that there is no relationship between lifetime exposure to general narrative fiction and ToM. This is clearest for the RMET, given that there is a $73 \%$ chance that preferring this hypothesis is the right choice. The results are somewhat less clear-cut for the Yoni task. Although there is a 30\% chance that the hypothesis that there is a positive relationship between the two is correct, the hypothesis that is most supported (PMP of .50) is the one that states that there is no relationship between ToM and exposure to general narrative fiction. General exposure to narrative fiction thus does not seem to be correlated positively with ToM.

Table 7 provides the analyses regarding the relation between exposure to literary and popular narrative fiction and ToM.

Table 7. Cumulative effects of literary/popular fiction exposure on ToM (RMET and Yoni)

\begin{tabular}{lcc}
\hline Hypothesis & RMET PMP & Yoni PMP \\
\hline 4-CE: Literary $>$ 0 AND literary $>$ popular & 0.15 & 0.55 \\
5-CE: Literary = popular & 0.34 & 0.15 \\
6-CE: Literary = 0 & 0.42 & 0.09 \\
Unconstrained & 0.09 & 0.21 \\
\hline
\end{tabular}

Interestingly, the results suggest that there is a difference between the two tasks that assess ToM in their relation to lifetime exposure to literary and popular narrative fiction. Although for the RMET there is the most support in the data for Hypothesis 6-CE, according to which there is no relationship between exposure to literary narrative fiction and ToM, for the Yoni task Hypothesis 4-CE was most supported. That is, the data suggest that there is a positive relationship between exposure to literary narrative fiction and Yoni task performance and that this relationship is stronger than the relationship between exposure to popular narrative fiction and Yoni task performance. These results are underscored by the correlations (see Table 3): Although the correlation between the RMET and the recognition of both literary and popular authors is close to zero, the Yoni task shows a dissociation between the two categories. Whereas Yoni task performance is not correlated with recognition of popular authors, this correlation is present (if relatively small, $r=.18$ ) for the recognition of literary authors. The more participants recognise literary authors, the higher their scores on the Yoni task, but higher recognition of popular authors does not have this effect on Yoni scores (and note that this holds even though there is a high correlation, $r=.71$, between recognition of popular and literary authors).

This dissociation between the RMET and the Yoni task with respect to the lifetime exposure hypotheses was surprising. On the basis of previous studies it was 
expected that scores on the ART in general and the literary ART in particular would be positively related to both measures of ToM. However, the current results suggest that only performance on the Yoni task is related to narrative fiction exposure and that this relationship is specific to literary narrative fiction. Given the fact that the Yoni task is comprised of various subcomponents, the following post-hoc analyses were aimed at investigating which of these subcomponents is most closely related to exposure to literary narrative fiction. As detailed in the Procedure section, the Yoni task assesses both understanding of cognitive and affective mental states at both the first and the second order level. In Table 8, the correlations between each of these subcomponents and the scores on the literary ART are provided (and, for completeness' sake, correlations with the popular ART score have also been added).

Table 8. Correlations ART Literary (and Popular) with Yoni Subcomponents

\begin{tabular}{lcccccccc}
\hline & Cognitive & Cognitive Cognitive & Affective & Affective Affective & $\begin{array}{c}\text { 1st } \\
\text { order }\end{array}$ & $\begin{array}{c}\text { 2nd } \\
\text { order }\end{array}$ \\
& 1st order & 2nd order & overall & 1st order & 2nd order & overall & overall overall \\
\hline $\begin{array}{l}\text { ART } \\
\text { literary }\end{array}$ & .11 & .18 & .21 & .02 & .09 & .09 & .08 & .18 \\
$\begin{array}{l}\text { ART } \\
\text { popular }\end{array}$ & .02 & .09 & .09 & -.06 & .01 & -.02 & -.02 & .07 \\
\hline
\end{tabular}

These results demonstrate that it is the cognitive subcomponent of the Yoni task that is most strongly correlated with ART literary scores. The affective subcomponents all have correlations close to zero with the ART literary score, but the overall cognitive score (which consists of the total score of the cognitive items measured at the first and second order level) reaches the highest correlation $(r=.21)$. This finding for the Yoni task is also in accord with the classification of the RMET as a measure of affective ToM. Evidently, the ability to attribute affective mental states to others (as indexed by the affective subcomponents of the Yoni task and the RMET) does not seem to be related to lifetime exposure to literary narrative fiction, but understanding of others' cognitive mental states (as indexed by the cognitive subcomponents of the Yoni task) is related to exposure to this type of fiction. Note, though, that this finding only holds for lifetime exposure to narrative fiction in relation to Yoni task performance. Reanalysis of the intervention data to consider only performance on the cognitive subcomponent of the Yoni task as a function of text condition yielded the same results as the analysis that considered full Yoni scores as a dependent variable (i.e., there was still by far the most support in the data for the hypothesis that there was no difference between text type groups in their performance on the Yoni task). 


\section{Discussion}

\section{Direct effects of exposure to (literary) narrative fiction on ToM}

Although some studies have not found reading literary narrative fiction to be an immediate ToM stimulant (Dijkstra et al., 2015; Panero et al., 2016), various other studies have suggested that there is a positive relation between the two (Kidd \& Castano, 2013; Kidd, et al., 2016; Pino \& Mazza, 2016). It is thus currently unclear whether reading literary narrative fiction directly enhances ToM or not. Furthermore, given that the studies that have found a direct effect of reading literature on ToM have generally selected works of literary narrative fiction on the basis of critical acclaim, it is currently also unclear what the 'active ingredient' (or ingredients) for ToM enhancement in literary narrative fiction might be. The present study thus considered both whether evidence for a direct link between reading literature and ToM would be found and whether the presence of literary 'gaps', as a marker of literariness, would be relevant in explaining a potential positive association between the two domains.

Results of the current study demonstrated that brief exposure to narrative fiction did not directly enhance participants' ToM scores, regardless of the text's literariness. All evaluated hypotheses that assumed that narrative fiction would be an effective ToM stimulant (be it narrative fiction in a general sense or dependent on its level of literariness) failed to gain any substantial support in the data. However, the data of the current study supported the hypothesis that there were no differences in the ToM scores of the various groups of participants. Given that a Bayesian confirmative approach was applied to the dataset, this outcome should not be interpreted as a classical null effect. That is, it is not the case that we simply cannot reject the null hypothesis, instead, the data show very clearly that there is evidence in favour of the hypothesis that the groups do not differ. The current study thus did not find evidence for direct effects of exposure to (literary) narrative fiction on ToM ability and the presence of literary 'gaps' was not found to play a role in the relationship between literary narrative fiction and ToM.

However, a number of caveats regarding this conclusion should be kept in mind. In the first place, the current study only used one text (and two adapted versions of this text) to act as a ToM stimulant. Regardless of the particular outcome, caution is needed in generalising findings obtained from one text to (literary) narrative fiction in general. Although this particular text was chosen because it was part of a set of texts that was found to be effective in Kidd and Castano (2013), it is possible that this particular text in itself does not lead to any ToM gains (in this respect it should also be noted that Kidd \& Castano, 2016, found this text to have a low reflective marker score, which suggests that it may not be a prototypical 
example of literary narrative fiction). Furthermore, it is also possible that the specific literary feature that characterised the text that we used (i.e., literary gaps regarding the source of specific utterances and the social situation of characters) may not be an important feature in stimulating ToM. Although the presence of gaps is a characteristic feature of literature and, from a theoretical point of view, this feature can plausibly be connected to ToM enhancement (Koopman \& Hakemulder, 2015), it could be that this feature (either the presence of gaps in general or as specifically operationalised in the current study) is simply not directly relevant in providing readers with ToM gains.

Alternatively, it is possible that the literary text (and potentially one or both of its adaptations) did have an immediate effect on the reader's ToM, but it was too subtle to pick up in our measures or with our sample size (although our measures and sample size were similar to those used in Kidd \& Castano, 2013). Studies that employ more texts and that manipulate other types of gap filling may thus provide a different picture of the relationship between literary gap-filling and direct ToM gains.

Future work might examine both text and reader variables to consider what factors determine whether a particular work of narrative fiction has a direct effect on the reader's ToM. On the reader side, it may be that some readers are more likely to profit from exposure to literary narrative fiction in terms of ToM gains. For instance, it may be the case that readers who are more prone to being transported into fictional worlds (i.e., readers with high levels of transportability) profit more from reading about complex others' mental states (cf. Bal \& Veltkamp, 2013). On the text side, a deeper investigation into the function of gaps may demonstrate that they are relevant after all. As argued above, literary gaps may occur in various forms, so perhaps different gap forms may be more powerful than the ones manipulated in the present study. Moreover, it is clear that there are many candidates for further investigation, such as: Foregrounding, polyvalence (or multiinterpretability), ambiguity, polyphony (the co-presence of different narratorial 'voices'), characters' roundness (e.g., having various contrasting traits), level of access to characters' inner worlds, the development of a character's personality etcetera. These may all be taken into consideration for future manipulation. Of course, none of these text qualities are unique to literature, but they are often assumed to constitute the degree of 'literariness' and seem to be dominantly found in literature, and less so in popular fiction. More importantly, it seems plausible that they contribute to the development of readers' ToM - if not after exposure to one short story, then maybe cumulatively, after years of literary reading. 


\section{Cumulative effects of exposure to narrative fiction over the lifetime on ToM}

Our results suggest that there is no relationship between lifetime exposure to general narrative fiction and ToM. Furthermore, the results of the analyses regarding literary narrative fiction exposure across the lifetime and ToM were somewhat mixed. Performance on the RMET (as a measure of affective ToM) was not related to exposure to literary narrative fiction (in contrast to the findings reported in Kidd \& Castano, 2016). However, there was a positive relationship between Yoni task scores (as a measure of both cognitive and affective ToM) and lifetime literary narrative fiction exposure and this relationship was found to be stronger than that between lifetime popular narrative fiction exposure and Yoni scores. Further analyses of the Yoni task results showed that the strongest positive correlation was present between performance on the cognitive component of the Yoni task and literary narrative fiction. These results thus suggest that lifetime exposure to literary narrative fiction is associated with higher levels of cognitive ToM (understanding what other people are thinking about), but not with affective ToM (understanding what other people are feeling). It is relevant to note here that if scores on the literary ART measure simply indicated more exposure to narrative fiction in general instead of being a specific indicator of exposure to literary narrative fiction, we would expect both the general ART scores and the literary ART scores to be related to ToM measures. As this is not the case (despite the high correlation between literary and popular ART scores), this suggests that there is something specific to exposure to literary narrative fiction that is responsible for this observed relationship.

Although the results initially seem to go against findings from previous studies that suggest that there is a relationship between ToM and general narrative fiction lifetime exposure (Djikic et al., 2013; Mar et al., 2006, 2009; Panero et al., 2016), the differences between the current study and previous work may not be profound. Potentially, the positive relation between general narrative fiction exposure and ToM that has been found in previous studies actually boils down to a positive correlation between exposure to literary narrative fiction and (cognitive) ToM. Given that previous studies on this topic have generally not divided narrative fiction exposure into literary and popular categories ${ }^{8}$ (but see Kidd \& Castano, 2016, for an exception), they may have primarily been measuring exposure to literary narrative fiction in their general narrative fiction exposure measure. The current study may then not have found a positive correlation between general narrative fiction and ToM because equal numbers of literary and popular

8. Instead, they have focused on including narrative fiction authors from various different genres, as well as distinguishing fiction from non-fiction authors. 
authors were present in the ART. Overall recognition scores could thus only be driven by literary narrative fiction exposure for maximally fifty percent, whereas this percentage may be (much) higher in other studies. Future research is needed to determine whether a distinction between literary and popular narrative fiction in exposure measures will consistently demonstrate stronger relations between literary narrative fiction and ToM as compared to popular narrative fiction.

Although we had expected lifetime exposure to literary narrative fiction to be positively related to ToM, we did not predict that this result would only hold for the Yoni task and not for the RMET, especially given that previous studies have found evidence for a positive relationship between narrative fiction exposure and RMET performance (e.g., Djikic et al., 2013; Panero et al., 2016) and even specifically between literary narrative fiction exposure and RMET performance (Kidd \& Castano, 2016). However, only for the Yoni task did we find that the ToM scores were positively correlated with literary narrative fiction exposure (and more strongly so than for popular narrative fiction exposure). Further analyses demonstrated that this relationship was primarily driven by the cognitive subcomponent of the Yoni task; correlations between literary narrative fiction exposure and the affective subcomponent were close to zero. There is thus an internal consistency in the findings: Those ToM measures that assess cognitive ToM (i.e., the cognitive subcomponents of the Yoni task) are positively correlated with literary narrative fiction exposure, whereas those that assess affective ToM (the affective subcomponents of the Yoni task and the RMET) are not. Our data thus suggests that exposure to literary narrative fiction is related to knowledge about others' thoughts and not so much to knowledge about others' emotions. Interestingly, although our results contrast with those of Kidd and Castano (2016) who do find a positive correlation between exposure to literary narrative fiction and RMET performance, the small number of other studies that have also made a distinction between cognitive vs. affective ToM in relation to (literary) narrative fiction exposure find similar results to the current study. For instance, Pino and Mazza (2016) found that exposure to literary narrative fiction positively affects mentalising (the ability to understand others' mental states), but not emotion sharing abilities (the capacity to emotionally resonate with others' feelings). The findings reported by Stansfield and Bunce (2014) also closely parallel the current results, as they did find a positive correlation between exposure to narrative fiction and cognitive ToM (as assessed using a questionnaire measuring perspective taking tendency), but did not find evidence for a correlation between narrative fiction exposure and scores on the RMET.

These results thus suggest that there might be a special relationship between exposure to (literary) narrative fiction and cognitive ToM. Indeed, it is known from the literature that cognitive and affective ToM are dissociable and are sub-served by different neural networks (Kalbe et al., 2010; Shamay-Tsoory \& Aharon-Peretz, 
2007; Shamay-Tsoory et al., 2007). In principle, it is thus possible that reading literary narrative fiction is specifically stimulating for readers' ability to understand the thoughts of others, whilst it may not have any demonstrable effects on their ability to understand others' emotions. It is characteristic of literature that its plotlines and character interactions are complex at the psychological level (Gerrig \& Rapp, 2004; Koopman \& Hakemulder, 2015; Van Peer, 1986). Potentially, this complexity pertains more to being able to fathom others' thoughts (at both the author and character level) than their emotions and thus exposure to literary narrative fiction is most effective at stimulating our cognitive ToM, whilst affective ToM is not enhanced.

However, it should be noted that given the correlational nature of the relationship between lifetime exposure to literary narrative fiction and cognitive ToM, it is not possible to draw firm conclusions regarding the causal direction of this link. Exposure to literary narrative fiction may have a beneficial effect on readers' ability to understand others' thoughts, but it is also possible that those readers who have a more advanced cognitive ToM are those who feel particularly drawn to literary narrative fiction. Additional intervention studies that assess the effects of literary narrative fiction specifically on cognitive vs. affective ToM are needed in order for stronger conclusions to be drawn regarding the relationship between exposure to literary narrative fiction and cognitive ToM.

In summary, although the results of the intervention component of the current study suggest that there are no directly measurable ToM gains to be had from a one-off encounter with a piece of literary narrative fiction (or at least not the short piece of literary narrative fiction used in this study), there do seem to be interesting links between lifetime exposure to literary narrative fiction and cognitive ToM. One short story by Chekhov might thus not get you very far as mental state understanding goes, but, chances are, the book smarts you gain from reading his collected works will spill over to your real world street smarts.

\section{Acknowledgements}

We would like to thank the Netherlands Organisation for Scientific Research (NWO) for its financial support (Vici grant \#277-89-001 and Gravitation grant \#024.001.003 to JvB and Talent grant \#406-12-001 to FK). We are also very grateful to Herbert Hoijtink for his help with the statistical analyses, to Ella Bosch and Marjan Bezemer for their assistance in conducting the study and to Chris van Run for his help with programming the tasks. 


\section{References}

Adrian, J. E., Clemente, R. A., Villanueva, L., \& Rieffe, C. (2005). Parent - child picture-book reading, mothers' mental state language and children's theory of mind. Journal of Child Language, 32(3), 673-686. doi: 10.1017/S0305000905006963

Aram, D., \& Aviram, S. (2009). Mothers' storybook reading and kindergartners' socioemotional and literacy development. Reading Psychology, 30(2), 175-194.

doi: $10.1080 / 02702710802275348$

Bal, P. M., \& Veltkamp, M. (2013). How does fiction reading influence empathy? An experimental investigation on the role of emotional transportation. PloS one, 8(1), e55341. doi: 10.1371/journal.pone.0055341

Barnes, J. L. (2012). Fiction, imagination, and social cognition: Insights from autism. Poetics, 40(4), 299-316. doi: 10.1016/j.poetic.2012.05.001

Baron-Cohen, S., Wheelwright, S., Hill, J., Raste, Y., \& Plumb, I. (2001). The "Reading the Mind in the Eyes" test revised version: A study with normal adults, and adults with Asperger syndrome or high-functioning autism. Journal of Child Psychology and Psychiatry, 42(2), 241-251. doi: 10.1111/1469-7610.00715

Black, J. E., \& Barnes, J. L. (2015). The effects of reading material on social and non-social cognition. Poetics, 52, 32-43. doi: 10.1016/j.poetic.2015.07.001

Chekhov, A. (1884/1978). A chameleon. In R. E. Matlow (Ed.), Anton Chekhov's short stories (pp. 1-3). New York, NY: Norton.

Chekhov, A. (1884/2014). De kameleon [The chameleon]. In Verzamelde werken 1 verhalen 1880-1885 (pp. 285-288). Amsterdam, The Netherlands: Van Oorschot.

Dijkstra, K., Verkoeijen, P. P. J. L., van Kuijk, I., Yee Chow, S., Bakker, A. \& Zwaan, R. A. (2015). Leidt het lezen van literaire fictie tot meer empathie? Een replicatiestudie [Does reading literature result in higher empathy? A replication study]. De Psycholoog, 50(10), 10-21.

Djikic, M., Oatley, K., \& Moldoveanu, M. C. (2013). Reading other minds: Effects of literature on empathy. Scientific Study of Literature, 3(1), 28-47. doi: 10.1075/ssol.3.1.06dji

Eugenides, J. (1993). The virgin suicides. New York, NY: Picador.

Fong, K., Mullin, J. B., \& Mar, R. A. (2013). What you read matters: The role of fiction genre in predicting interpersonal sensitivity. Psychology of Aesthetics, Creativity, and the Arts, 7(4), 370-376. doi: 10.1037/aoo34084

Gamannossi, B. A., \& Pinto, G. (2014). Theory of mind and language of mind in narratives: Developmental trends from kindergarten to primary school. First Language, 34(3), 262272. doi: 10.1177/0142723714535875

Gerrig, R. \& Rapp, D. (2004). Psychological processes underlying literary impact. Poetics Today, 25(2), 265-281. doi: 10.1215/03335372-25-2-265

Hakemulder, J. (2000). The moral laboratory: Experiments examining the effects of reading literature on social perception and moral self-concept. Amsterdam, The Netherlands: John Benjamins Publishing.

Harlow, L. L., Mulaik, S. A., \& Steiger, J. H. (1997). What if there were no significance tests? Mahwah, NJ: Erlbaum.

Hoijtink, H. (2012). Informative hypotheses: Theory and practice for behavioral and social scientists. Boca Raton, FL: CRC.

Iser, W. (1975). Die Appellstruktur der Texte. In R. Warning (Ed.), Rezeptionsästhetik: Theorie und Praxis (pp. 228-252). Munich, Germany: Fink. 
Iser, W. (1978). The act of reading: A theory of aesthetic response. Baltimore, MD: Johns Hopkins University Press.

Iser, W. (1988). The reading process: A phenomenological approach. In D. Lodge (Ed.), Modern criticism and thought: A reader (pp. 279-299). London, United Kingdom: Longman.

Kalbe, E., Schlegel, M., Sack, A. T., Nowak, D. A., Dafotakis, M., Bangard, C., ... \& Kessler, J. (2010). Dissociating cognitive from affective theory of mind: A TMS study. Cortex, 46(6), 769-780. doi: 10.1016/j.cortex.2009.07.010

Keen, S. (2007). Empathy and the novel. New York, NY: Oxford University Press.

Kidd, D. C., \& Castano, E. (2013). Reading literary fiction improves theory of mind. Science, 342(6156), 377-380. doi: 10.1126/science.1239918

Kidd, D., \& Castano, E. (2016). Different stories: How levels of familiarity with literary and genre fiction relate to mentalizing. Psychology of Aesthetics, Creativity, and the Arts, Advance online publication. doi: 10.1037/acaooooo69

Kidd, D. C., \& Castano, E. (2017). Panero et al. (2016): Failure to replicate methods caused the failure to replicate results. Journal of Personality and Social Psychology, 112(3), e1-e4.

doi: $10.1037 /$ pspaooooo72

Kidd, D., Ongis, M., \& Castano, E. (2016). On literary fiction and its effects on theory of mind. Scientific Study of Literature, 6(1), 42-58. doi: 10.1075/ssol.6.1.04kid

Koopman, E. M. E. (2015a). Empathic reactions after reading: The role of genre, personal factors and affective responses. Poetics, 50, 62-79. doi: 10.1016/j.poetic.2015.02.008

Koopman, E. M. E. (2015b). How texts about suffering trigger reflection: Genre, personal factors and affective responses. Psychology of Aesthetics, Creativity, and the Arts, 9(4), 430-441. doi: $10.1037 /$ acaoooooo6

Koopman, E. M. E. (2016a). Reading suffering. Rotterdam, The Netherlands: ERMeCC, Erasmus Research Center for Media, Communication and Culture

Koopman, E. M. E. (2016b). Effects of "literariness" on emotions and on empathy and reflection after reading. Psychology of Aesthetics, Creativity, and the Arts, 10(1), 82-98.

doi: 10.1037/acaooooo41

Koopman, E. M. E., \& Hakemulder, F. (2015). Effects of literature on empathy and self-reflection: A theoretical-empirical framework. Journal of Literary Theory, 9(1), 79-111. doi: 10.1515/jlt-2015-0005

Kluytmans, A., van de Schoot, R., Mulder, J., \& Hoijtink, H. (2012). Illustrating Bayesian evaluation of informative hypotheses for regression models. Frontiers in Psychology, 3(2), 1-11. doi: 10.3389/fpsyg.2012.00002

Mar, R. A., \& Oatley, K. (2008). The function of fiction is the abstraction and simulation of social experience. Perspectives on Psychological Science, 3(3), 173-192.

doi: 10.1111/j.1745-6924.2008.00073.x

Mar, R. A., Oatley, K., Hirsh, J., dela Paz, J., \& Peterson, J. B. (2006). Bookworms versus nerds: Exposure to fiction versus non-fiction, divergent associations with social ability, and the simulation of fictional social worlds. Journal of Research in Personality, 40(5), 694-712. doi: 10.1016/j.jrp.2005.08.002

Mar, R. A., Oatley, K., \& Peterson, J. B. (2009). Exploring the link between reading fiction and empathy: Ruling out individual differences and examining outcomes. Communications, 34(4), 407-428. doi: 10.1515/COMM.2009.025

Mol, S. E., \& Bus, A. G. (2011). To read or not to read: A meta-analysis of print exposure from infancy to early adulthood. Psychological Bulletin, 137(2), 267-296. doi: 10.1037/aoo21890 
Moore, M., \& Gordon, P. C. (2015). Reading ability and print exposure: Item response theory analysis of the author recognition test. Behavior Research Methods, 47(4), 1095-1109. doi: 10.3758/s13428-014-0534-3

Mulder, J., Hoijtink, H. \& Klugkist, I. (2009). Equality and inequality constrained multivariate linear models: Model selection using constrained posterior priors. Journal of Statistical Planning and Inference, 140(4), 887-906. doi: 10.1016/j.jspi.2009.09.022

Mulder, J., Hoijtink, H., \& de Leeuw, C. (2012). BIEMS: A Fortran 90 program for calculating Bayes factors for inequality and equality constrained models. Journal of Statistical Software, 46(2), 1-39. doi: 10.18637/jss.v046.io2

Mulder, J., Klugkist, I. G., Schoot, A. G. J. van de, Meeus, W. H. J., Selfhout, M. H. W. \& Hoijtink, H. J. A. (2009). Informative hypotheses for repeated measurements: A Bayesian approach. Journal of Mathematical Psychology, 53(6), 530-546. doi: 10.1016/j.jmp.2009.09.003

Mumper, M. L. \& Gerrig, R. J. (2016). Leisure reading and social cognition: A meta-analysis. Psychology of Aesthetics, Creativity, and the Arts, 11(1), 109-120. doi: 10.1037/acaooooo89

Oatley, K. (1999a). Why fiction may be twice as true as fact: Fiction as cognitive and emotional simulation. Review of General Psychology, 3(2), 101. doi: 10.1037/1089-2680.3.2.101

Oatley, K. (1999b). Meetings of minds: Dialogue, sympathy, and identification, in reading fiction. Poetics, 26(5-6), 439-454. doi: 10.1016/S0304-422X(99)0o011-X

Oatley, K., \& Mar, R. A. (2005). Evolutionary pre-adaptation and the idea of character in fiction. Journal of Cultural and Evolutionary Psychology, 3(2), 179-194. doi: 10.1556/JCEP.3.2005.2.5

Panero, M. E., Weisberg, D. S., Black, J., Goldstein, T. R., Barnes, J. L., Brownell, H., \& Winner, E. (2016). Does reading a single passage of literary fiction really improve theory of mind? An attempt at replication. Journal of Personality and Social Psychology, 111(5), e46-e54. doi: 10.1037/pspaooooo64

Peskin, J., \& Astington, J. W. (2004). The effects of adding metacognitive language to story texts. Cognitive Development, 19(2), 253-273. doi: 10.1016/j.cogdev.2004.01.003

Pino, M. C., \& Mazza, M. (2016). The use of "literary fiction" to promote mentalizing ability. PloS one, 11(8), e0160254. doi: 10.1371/journal.pone.0160254

Ratner, N. K., \& Olver, R. R. (1998). Reading a tale of deception, learning a theory of mind? Early Childhood Research Quarterly, 13(2), 219-239. doi: 10.1016/So885-2006(99)80036-2

Rosnow, R. L., \& Rosenthal, R. (1989). Statistical procedures and the justification of knowledge in psychological science. American Psychologist, 44(10), 1276-1284. doi: 10.1037/0003-066X.44.10.1276

Shamay-Tsoory, S. G., \& Aharon-Peretz, J. (2007). Dissociable prefrontal networks for cognitive and affective theory of mind: A lesion study. Neuropsychologia, 45(13), 3054-3067. doi: 10.1016/j.neuropsychologia.2007.05.021

Shamay-Tsoory, S. G., Shur, S., Barcai-Goodman, L., Medlovich, S., Harari, H., \& Levkovitz, Y. (2007). Dissociation of cognitive from affective components of theory of mind in schizophrenia. Psychiatry Research, 149(1), 11-23. doi: 10.1016/j.psychres.2005.10.018

Shamay-Tsoory, S. G., Tibi-Elhanany, Y., \& Aharon-Peretz, J. (2007). The green-eyed monster and malicious joy: The neuroanatomical bases of envy and gloating (schadenfreude). Brain, 130(6), 1663-1678. doi: 10.1093/brain/awmo93

Stanovich, K. E., \& West, R. F. (1989). Exposure to print and orthographic processing. Reading Research Quarterly, 24(4), 402-433. doi: 10.2307/747605

Stansfield, J. \& Bunce, L. (2014). The relationship between empathy and reading fiction: Separate roles for cognitive and affective components. Journal of European Psychology Students, 5(3), 9-18. doi: 10.5334/jeps.ca 
Sugiyama, M. S. (2001). Food, foragers, and folklore: The role of narrative in human subsistence. Evolution and Human Behavior, 22(4), 221-240. doi: 10.1016/S1090-5138(01)00063-0

van Beem, J. (2015). Kleur bekennen [Follow suit]. National Geographic, 9, 118-130.

van de Schoot, R., Kaplan, D., Denissen, J., Asendorpf, J. B., Neyer, F. J., \& Aken, M. A. (2014).

A gentle introduction to Bayesian analysis: Applications to developmental research. Child Development, 85(3), 842-860. doi: 10.1111/cdev.12169

van de Schoot, R., Mulder, J., Hoijtink, H., Van Aken, M. A., Semon Dubas, J., Orobio de Castro, B., .. \& Romeijn, J. W. (2011). An introduction to Bayesian model selection for evaluating informative hypotheses. European Journal of Developmental Psychology, 8(6), 713-729. doi: 10.1080/17405629.2011.621799

Van Peer, W. (1986). Pulp and purpose. Stylistic analysis as an aid to a theory of texts. In T. D'Haen (Ed.), Linguistics and the study of literature (pp. 268-286). Amsterdam, The Netherlands: Rodopi.

Van Peer, W. (1989). Quantitative studies of literature. A critique and an outlook. Computers and the Humanities, 23(4), 301-307. doi: 10.1007/BFo2176635

West, R. F., Stanovich, K. E., \& Mitchell, H. R. (1993). Reading in the real world and its correlates. Reading Research Quarterly, 28(1), 34-50. doi: 10.2307/747815

Zunshine, L. (2006). Why we read fiction: Theory of mind and the novel. Columbus, OH: Ohio State University Press.

\section{Appendix. Texts}

\section{A Chameleon, original version (English version provided here, Dutch translation used)}

The police superintendent Otsjoemelov is walking across the market square wearing a new overcoat and carrying a parcel under his arm. A red-haired policeman strides after him with a sieve filled to the rim with confiscated gooseberries. There is silence all around ... Not a soul in the square ... The open doors of the shops and taverns appear disconsolately, like hungry mouths into the wide world; there is not even a beggar near them.

"So you bite, you damned brute?" Otsjoemelov hears suddenly. "Lads, don't let it go! Biting is prohibited nowadays! Hold it! Ah ... ah!"

There is the sound of a dog yelping. Otsjoemelov looks in the direction of the sound and sees a dog, hopping on three legs and looking about it, run out of merchant Pitsjoegin's timberyard. A man in a starched cotton shirt, with his waistcoat unbuttoned, is chasing it. The man runs after the animal, and throwing his body forward falls down and seizes the dog by its hind legs. Once more there is a yelping and a sound of “Don't let go!" Sleepy countenances are protruded from the shops, and soon a crowd, as if out of nowhere, is gathered round the timber-yard.

"It looks like a row, your honour ..." says the policeman.

Otsjoemelov makes half a turn to the left and strides towards the crowd. He sees the aforementioned man in the unbuttoned waistcoat standing close by the gate of the timber-yard, holding his right hand in the air and displaying a bleeding finger to the crowd. On his half-drunken face there is plainly written: "I'll pay you back, you rogue!" and indeed the very finger has the look of a flag of victory. In this man Otsjoemelov recognises Chrjoekin, the goldsmith. The culprit who has caused the sensation, a white borzoy puppy with a sharp muzzle and a yellow patch 
on its back, is sitting on the ground with its fore-paws outstretched in the middle of the crowd, trembling all over. There is an expression of misery and terror in its tearful eyes.

"What's it all about?" Otsjoemelov inquires, pushing his way through the crowd. "What are you here for? Why are you waiving your finger?.. Who shouted?"

"I was walking along here, not interfering with anyone, your honour ..." Chrjoekin begins, coughing into his fist. "Because of firewood, with Mitri Mitritsj, this low brute for no rhyme or reason bit my finger ... You must excuse me, I am a working man ... Mine is fine work. I must have damages, for I shan't be able to use this finger for a week, maybe ... It's not even the law, your honour, that one should put up with it from a beast ... If everyone is going to be bitten, life on earth won't be worth living ..."

"Hm!.. Good ..." says Otsjoemelov sternly, coughing and raising his eyebrows. "Good ... Whose dog is it? I won't let this pass! I'll teach you to let your dogs run all over the place! It's time these gentry were looked after, if they won't obey the regulations! When he's fined, the blackguard, I'll teach him what it means to keep dogs and such stray cattle! I'll give him a lesson!.. Jeldyrin," says the superintendent, addressing the policeman, "find out whose dog this is and draw up a report! And the dog must be destroyed. Without delay! It's sure to be mad ... Whose dog is it? I ask!"

"I fancy it's General Zjigalov's," says someone in the crowd.

“General Zjigalov's? Hm!.. Help me off with my coat, Jeldyrin ... it’s frightfully hot! It must be a sign of rain ... There's one thing I can't make out, how it came to bite you?" Otsjoemelov asks Chrjoekin. "Surely he couldn't reach your finger. He's a little dog, and you are a great hulking fellow! You must have scratched your finger with a nail, and then the idea struck you to get damages for it. We all know ... your sort! I know you devils!"

"He put a cigarette in its face, your honour, for a joke, but it had the sense to snap at him ... He is a nonsensical fellow, your honour!"

"That's a lie, Squinteye! You didn't see, so why tell lies about it? His honour is a wise gentleman, and will see who is telling lies and who is telling the truth, as in God's sight ... And if I am lying let the court decide. It's written in the law ... We are all equal nowadays. My own brother is in the gendarmes ... if you want to know ..."

"Shut your mouth!"

"No, that's not the General's dog," says the policeman, with profound conviction, "the General hasn't got ones like that. His are mostly setters."

"Do you know that for a fact?"

"Yes, your honour."

"I know it, too. The General has valuable dogs, thoroughbred, and this is goodness knows what! No coat, no shape ... a low creature ... And to keep a dog like that?! ... Where's the sense of it. If a dog like that were to turn up in Petersburg or Moscow, do you know what would happen? They would not worry about the law, but at once - away with it! You've been injured, Chrjoekin, and we can't let the matter drop ... We must give them a lesson! It is high time ..."

"Yet maybe it is the General's ..." says the policeman, thinking aloud. "It's not written on its face ... I saw one like it the other day in his yard."

"It's the General's, that's certain!" says a voice in the crowd.

"Hm!.. help me on with my overcoat, Jeldyrin, my lad ... The wind's getting up ... I am shivering ... Take the dog to the General, and inquire there. Say I found it and sent you ... And tell them not to let it out into the street ... It may be a valuable dog, and if every swine goes sticking a cigar to its nose, it will soon be ruined. A dog is a delicate animal ... And you put your hand down, you blockhead! It's no use your displaying your fool of a finger! It's your own fault! ...." 
"Here comes the General's cook, ask him ... Hi, Prochor! Come here, my dear man! Do you see that dog? ... Is it yours?"

"Are you kidding? We have never had one like that!"

“There's no need to waste time asking," says Otsjoemelov. "It's a stray dog! There's no need to waste time talking about it ... If I say it's a stray dog, a stray dog it is ... It must be destroyed, that's all about it."

"It is not our dog," Prochor goes on. "It belongs to the General's brother, who arrived the other day. Our master does not care for hounds. But his honour is fond of them ..."

"You don't say his brother has arrived? Vladimir Ivanytsj?" inquires Otsjoemelov, and his whole face beams with an ecstatic smile. "Well, I never! And I didn't know! Has he come on a visit?

"Yes ..."

"Well, I never ... He was missing his brother ... And there I didn't know! So this is his honour's dog? Delighted to hear it ... Take it ... Good dog ... A lively creature. ... Snapped at this fellow's finger! Ha-ha-ha ... Come on, why are you shivering? Grrr ... Grrr ... The rogue's angry $\ldots$ a nice little pup."

Prochor calls the dog and walks away from the timber-yard with it. The crowd laughs at Chrjoekin.

"I'll get you!" Otsjoemelov threatens him, and wrapping himself in his greatcoat, goes on his way across the square.

\section{A Chameleon, limited manipulation version (English version provided here, Dutch translation used; changes marked in boldface)}

The police superintendent Otsjoemelov is walking across the market square wearing a new overcoat and carrying a parcel under his arm. A The red-haired policeman Leldyrin strides after him with a sieve filled to the rim with confiscated gooseberries. There is silence all around ... Not a soul in the square ... The open doors of the shops and taverns appear disconsolately, like hungry mouths into the wide world; there is not even a beggar near them.

"So you bite, you damned brute?" Otsjoemelov hears suddenly. "Lads, don't let it that dog go! Biting is prohibited nowadays! Hold it! Ah ... ah!"

There is the sound of a dog yelping. Otsjoemelov looks in the direction of the sound and sees a dog, hopping on three legs and looking about it, run out of merchant Pitsjoegin's timberyard. A man in a starched cotton shirt, with his waistcoat unbuttoned, is chasing it- The man; it is the goldsmith Chrjoekin. Chrjoekin runs after the animal, and throwing his body forward falls down and seizes the dog by its hind legs. Once more there is a yelping and a sound of "Don't let go!" Sleepy countenances are protruded from the shops, and soon a crowd, as if out of nowhere, is gathered round the timber-yard.

"It looks like a row, your honour ..." says the policeman Jeldyrin to Otsjoemelov.

Otsjoemelov makes half a turn to the left and strides towards the crowd. He sees the aforementioned man in the unbuttoned waisteoat Chrjoekin standing close by the gate of the timberyard, holding his right hand in the air and displaying a bleeding finger to the crowd. On his halfdrunken face there is plainly written: "I'll pay you back, you rogue!" and indeed the very finger has the look of a flag of victory. In this man Otsjoemelov recognises Chrjoekin, the goldsmith. The culprit who has caused the sensation, a white borzoy puppy with a sharp muzzle and a yel- 
low patch on its back, is sitting on the ground with its fore-paws outstretched in the middle of the crowd, trembling all over. There is an expression of misery and terror in its tearful eyes.

"What's it all about?" Otsjoemelov inquires, pushing his way through the crowd. "What are you here for? Why are you waiving your finger?.. Who shouted?"

"I was walking along here, not interfering with anyone, your honour ..." Chrjoekin begins, coughing into his fist. "Because of firewood, with Mitri Mitritsj, this low brute for no rhyme or reason bit my finger ... You must excuse me, I am a working man ... Mine is fine work. I must have damages, for I shan't be able to use this finger for a week, maybe ... It's not even the law, your honour, that one should put up with it from a beast ... If everyone is going to be bitten, life on earth won't be worth living ..."

"Hm!.. Good ..." says Otsjoemelov sternly, coughing and raising his eyebrows. "Good ... Whose dog is it? I won't let this pass! I'll teach you to let their dogs run all over the place! It's time these gentry were looked after, if they won't obey the regulations! When he's fined, the blackguard, I'll teach him what it means to keep dogs and such stray cattle! I'll give him a lesson!.. Jeldyrin," says the superintendent, addressing the policeman, "find out whose dog this is and draw up a report! And the dog must be destroyed. Without delay! It's sure to be mad ... Whose dog is it? I ask!"

"I fancy it's General Zjigalov's," says someone in the crowd.

“General Zjigalov's? Hm!.. Help me off with my coat, Jeldyrin ... it’s frightfully hot! It must be a sign of rain ... There's one thing I can't make out, how it came to bite you?" Otsjoemelov asks Chrjoekin. "Surely he couldn't reach your finger. He's a little dog, and you are a great hulking fellow! You must have scratched your finger with a nail, and then the idea struck you to get damages for it. We all know ... your sort! I know you devils!"

"He put a cigarette in its face, your honour, for a joke," says someone in the crowd. "But but it had the sense to snap at him ... He is a nonsensical fellow, your honour!"

“That's a lie, Squinteye!" Chrjoekin calls out. "You didn't see, so why tell lies about it? His honour is a wise gentleman, and will see who is telling lies and who is telling the truth, as in God's sight ... And if I am lying let the court decide. It's written in the law ... We are all equal nowadays. My own brother is in the gendarmes ... if you want to know ..."

"Shut your mouth!" Otsjoemelov orders.

"No, that's not the General's dog," says the policeman Jeldyrin, with profound conviction, "the General hasn't got ones like that. His are mostly setters."

"Do you know that for a fact?" Otsjoemelov asks.

"Yes, your honour."

"I know it, too:." says Otsjoemelov. "The General has valuable dogs, thoroughbred, and this is goodness knows what! No coat, no shape ... a low creature ... And to keep a dog like that?! ... Where's the sense of it. If a dog like that were to turn up in Petersburg or Moscow, do you know what would happen? They would not worry about the law, but at once - away with it! You've been injured, Chrjoekin, and we can't let the matter drop ... We must give them a lesson! It is high time ..."

"Yet maybe it is the General's ..." says the polieeman Jeldyrin, thinking aloud. "It's not written on its face ... I saw one like it the other day in his yard."

"It's the General's, that's certain! " says a voice in the crowd.

"Hm!.. help me on with my overcoat, Jeldyrin, my lad ...” Otsjoemelov requests Jeldyrin. “The wind's getting up ... I am shivering ... Take the dog to the General, and inquire there. Say I found it and sent you ... And tell them not to let it out into the street ... It may be a valuable $\mathrm{dog}$, and if every swine goes sticking a cigar to its nose, it will soon be ruined. A dog is a delicate 
animal ... And you Chrjoekin, put your hand down, you blockhead! It's no use your displaying your fool of a finger! It's your own fault!...."

"Here comes the General's cook, ask him ...”Jeldyrin suggests. "Hi, Prochor! Come here, my dear man! Do you see that dog? ... Is it yours?”

"Are you kidding? We have never had one like that!" Prochor says.

“There's no need to waste time asking," says Otsjoemelov. "It's a stray dog! There's no need to waste time talking about it ... If I say it's a stray dog, a stray dog it is ... It must be destroyed, that's all about it."

"It is not our dog," Prochor goes on. "It belongs to the General's brother, who arrived the other day. Our master does not care for hounds. But his honour is fond of them ..."

"You don't say his brother has arrived? Vladimir Ivanytsj?" inquires Otsjoemelov, and his whole face beams with an ecstatic smile. "Well, I never! And I didn't know! Has he come on a visit?

\section{"Yes ..." Prochor starts.}

"Well, I never ... He was missing his brother ..." Otsjoemelov continues. “And there I didn't know! So this is his honour's dog? Delighted to hear it ... Take it ... Good dog ... A lively creature .... Snapped at this fellow's finger! Ha-ha-ha ... Come on, why are you shivering? Grrr ... Grrr ... The rogue's angry ... a nice little pup."

Prochor calls the dog and walks away from the timber-yard with it. The crowd laughs at Chrjoekin.

"I'll get you!" Otsjoemelov threatens him, and wrapping himself in his greatcoat, goes on his way across the square.

\section{A Chameleon, extensive manipulation version (English version provided here,}

\section{Dutch translation used; changes marked in boldface)}

The police superintendent Otsjoemelor Jansen is walking across the market square wearing a new overcoat and carrying a parcel under his arm. A The red-haired policeman $\underline{\text { De Vries }}$ strides after him with a sieve filled to the rim with confiseated gooseberries. There is silence all around ... Not a soul in the square ... The open doors of the shops and taverns appear disconsolately, like hungry mouths into the wide world; there is not even a beggar near them.

"So you bite, you damned brute?" Otsjoeme Jansen hears goldsmith Tiggelaar shout suddenly. "Lads, don't let it that dog go! Biting is prohibited nowadays! Hold it! Ah ... ah!"

There is the sound of a dog yelping. Otsjoemetonsen looks in the direction of the sound and sees a dog, hopping on three legs and looking about it, run out of merehant Pitsjogin's a timber-yard. A man The goldsmith Tiggelaar in a starched cotton shirt, with his waistcoat unbuttoned, is chasing it. The man Tiggelaar runs after the animal, and throwing his body forward falls down and seizes the dog by its hind legs. Once more there is a yelping and a sound of "Don't let go!" Sleepy countenances are protruded from the shops, and soon a crowd, as if out of nowhere, is gathered round the timber-yard.

"It looks like a row, your honour boss!.." says the policeman De Vries.

Otsjoemelor Jansen makes half a turn to the left and strides towards the crowd. He sees the aforementioned man in the unbuttoned waistcoat Tiggelaar standing close by the gate of the timber-yard, holding his right hand in the air and displaying a bleeding finger to the crowd. On his half-drunken face there is plainly written: "I'll pay you back, you rogue!" and indeed the very finger has the look of a flag of victory. In this man Otsjoemelorecognises Chrjoekin, 
the goldsmith. The culprit who has caused the sensation, a white borzoy puppy with a sharp muzzle and a yellow patch on its back, is sitting on the ground with its fore-paws outstretched in the middle of the crowd, trembling all over. There is an expression of misery and terror in its tearful eyes.

"What's it all about?" Otsjoemelor Jansen inquires, pushing his way through the crowd. "What are you here for? Why are you waiving your finger?.. Who shouted?"

"I was walking along here, not interfering with anyone, hour hour inspector ..." Chrjoekin Tiggelaar begins, coughing into his fist. "Beeatsse of flret, Mitri Mitritsj, this This low brute for no rhyme or reason bit my finger...!.. You must excuse me, I am a working man ... Mine is fine work. I must have damages, for I shan't be able to use this finger for a week, maybe ... It's not even the law, inspector, that one should put up with it from a beast ... If everyone is going to be bitten, life on earth won't be worth living ..."

"Hm!.. Good ..." says Otsjoemet Jansen sternly, coughing and raising his eyebrows. "Good ... Whose dog is it? I won't let this pass! I'll teach you to let their dogs run all over the place! It's time these gentry were looked after, if they won't obey the regulations! When he's fined, the blackguard, I'll teach him what it means to keep dogs and such stray cattle! I'll give him a lesson!.. Jeldyrin De Vries," says the superintendent, addressing the policeman, "find out whose dog this is and draw up a report! And the dog must be destroyed. Without delay! It's sure to be mad ... Whose dog is it? I ask!"

"I fancy it's General Zjigalov's chief inspector Jacobs'," says someone in the crowd.

"General Zijigalor's Chief inspector Jacobs"? Hm!.. Help me off with my coat, fetdyrin De Vries ... it's frightfully hot! It must be a sign of rain ... There's one thing I can't make out, how it came to bite you?" Өetsjoemeł Jansen asks Chrjoekin Tiggelaar. "Surely he couldn't reach your finger. He's a little dog, and you are a great hulking fellow! You must have scratched your finger with a nail, and then the idea struck you to get damages for it. We all know ... your sort! I know you devils!"

"He put a cigarette in its face, hour inspector, for a joke," says someone in the crowd. "But but it had the sense to snap at him ... He is a nonsensical fellow, spector!"

“That's a lie, Squinteye!” Tiggelaar calls out. "You didn't see, so why tell lies about it? His honour The inspector is a wise gentleman, and will see who is telling lies and who is telling the truth, as in God's sight ... And if I am lying let the court decide. It's written in the law ... We are all equal nowadays. My own brother is in the gendarmes ... if you want to know ..."

"Shut your mouth!" Jansen orders.

"No, that's not the General's chief inspector's dog," says the policeman De Vries, with profound conviction, "the General chief inspector hasn't got ones like that. His are mostly setters."

"Do you know that for a fact?" Jansen asks.

"Yes, your honour boss."

"I know it, too:", says Jansen. "The chief inspector the General has valuable dogs, thoroughbred, and this is goodness knows what! No coat, no shape ... a low creature ... And to keep a dog like that?! ... Where's the sense of it. If a dog like that were to turn up in Petersburg or Moscow, do you know what would happen? They would not worry about the law, but at once away with it! You've been injured, Chrjoekin Tiggelaar, and we can't let the matter drop ... We must give them a lesson! It is high time ..."

"Yet maybe it is the General's chief inspector's ..." says the policeman De Vries, thinking aloud. "It's not written on its face ... I saw one like it the other day in his yard."

"It's the General's chief inspector's, that's certain! "says a voice in the crowd. 
"Hm!.. help me on with my overcoat, feldyrin De Vries, my lad ...”Jansen requests De Vries. “The wind's getting up ... I am shivering ... Take the dog to the General's chief inspector, and inquire there. Say I found it and sent you .... And tell them not to let it out into the street ... It may be a valuable dog, and if every swine goes sticking a cigar to its nose, it will soon be ruined. A dog is a delicate animal ... And you Tiggelaar, put your hand down, you blockhead! It's no use your displaying your fool of a finger! It's your own fault! ....”

"Here comes the General's chief inspector's gardener, ask him ..." De Vries remarks. "Hi, Pren Nederhof! Come here, my dear man! Do you see that dog? ... Is it yours?"

"Are you kidding? We have never had one like that!" says Nederhof.

"There's no need to waste time asking," says Otsjometor Jansen. "It's a stray dog! There's no need to waste time talking about it ... If I say it's a stray dog, a stray dog it is ... It must be destroyed, that's all about it."

"It is not our dog," Prochor Nederhof goes on. "It belongs to the General's chief inspector's brother, who arrived the other day. Our master chief inspector does not care for hounds. But his honour is fond of them ..."

"You don't say his brother has arrived? Vladimir Ivanytsj Cas Jacobs?" inquires Otsjoemelov Jansen, and his whole face beams with an ecstatic smile. "Well, I never! And I didn't know! Has he come on a visit?

"Yes ..." Nederhof starts.

"Well, I never ... He was missing his brother ...” Jansen continues. “And there I didn't know! So this is his honour's dog? Delighted to hear it ... Take it ... Good dog ... A lively creature .... Snapped at this fellow's finger! Ha-ha-ha ... Come on, why are you shivering? Grrr ... Grrr ... The rogue's angry ... a nice little pup."

Proch Nederhof calls the dog and walks away from the timber-yard with it. The crowd laughs at Ehrjoekin Tiggelaar.

"I'll get you!" Otsjoemelor Jansen threatens him, and wrapping himself in his greatcoat, goes on his way across the square.

\section{True Colours, non-fictional text (English translation provided here, Dutch original used)}

There are but few animals with such an extensive collection of anatomical curiosities as the chameleon. It has a tongue that is longer than its body; with it, it can attack an insect in a fraction of a second. It also has telescopic eyes in round sockets that can move independently. It can use its toes as a pair of tweezers, has lumps on its forehead and snout, strange bulges on its nose, and it has a skinfold in its neck that resembles the lace collar of a sixteenth century nobleman.

Its most typical trait amazed people as far back as the days of Aristotle: its ability to change colour. It is a widespread myth that the chameleon takes on the colour of everything it touches. Sometimes such a change of colour does make him stand out less in his environment, but in reality it is a physiological reaction that serves as a means of communication. By means of colour, the lizard expresses everything it feels, like attraction, rivalry, or threat from its environment.

At least, that is the current view. "Even though chameleons have interested people for years, they are still surrounded by a lot of mystery", says Christopher Anderson, biologist and chameleon expert of Brown University in Rhode Island. "We still don't know how their mechanisms work" - from the rapid tongue movements to the changing skin colour. 
In recent years, important discoveries have been made through observations of chameleons in captivity. Their future in the wild is however highly uncertain.

According to the most recent Red List of the International Union for Conservation of Nature (IUCN), that was published November last year, at least half of all chameleon species are considered to be 'endangered' or 'near endangered'. Anderson is part of the chameleon work group of the IUCN, just as biologist Krystal Tolley. She does field work in the south of Africa, where she has discovered new chameleon species and is mapping their disappearing habitat.

Approximately 40 percent of the over two hundred known chameleon species lives on the island of Madagascar, most others in continental Africa. Over 20 percent of the known species has only been discovered in the past fifteen years.

Anderson closely studies the feeding behaviour of the chameleon. Using a camera that captures three thousand frames per second, he has shot 0.56 seconds of footage of a chameleon eating a cricket. He has stretched out that footage to create an instruction video of 28 seconds, which shows exactly how the animal uses its tongue.

In its throat sac the chameleon has a tongue-bone surrounded by elastic connective tissue in a tubular acceleration-muscle. As soon as the chameleon sees an insect, it sticks out its tongue slightly, which causes the muscle to contract and the tongue to shoot out as if it iaunched by a catapult. The tip of the tongue functions as a suction cup that grabs onto the prey, after which the tongue slides back inside.

But we are far from knowing everything about the mechanism of the tongue, says Anderson. His research suggests that some chameleons can extend their tongue even faster and farther than was previously thought.

Also with regards to the changing skin colour there are new insights - especially since the publication earlier this year of the research of Michel Milinkovitch, evolutionary geneticist and biophysicist at the Université de Genève. For a long time, the dominant theory was that the chameleon changes its colour by effusing pigment cells in the skin through paper-thin cell extensions. Milinkovitch does not buy this theory, because many green chameleons don't even have green pigments in their skin.

That is why he decided to "bring physics and biology together" in his team, he says. Under a layer of skin with pigment cells they discovered another layer with cells that contain nanocrystals, ordered in a triangular grid.

By exposing skin samples of chameleons to pressure and chemicals, the scientists discovered that the pattern of crystals can be adjusted by increasing or decreasing the distance between the crystals. And that has an effect on the light that the crystals reflect. With an increase of the distance between the crystals, the reflection of light changes from blue to green, yellow, and orange and finally to red - the kaleidoscopic colour show that can be clearly seen on some panther chameleons when a calm disposition changes to aggression or arousal.

According to a study from 2014, chameleons have also developed the ability to show submission through the changing of their skin colour, because due to their "slow tempo they are hardly capable of getting away quickly from dominant conspecifics".

Although all chameleons change colour, some species do not do so in a way that is spectacular enough to scare away their rivals. Fortunately the animals have another intimidation technique: they can make themselves appear bigger. They make their body longer and higher by expanding their ribcage. They can also make themselves more massive by rolling up their tail and using their tongue to puff out their throat.

To escape the birds and snakes that hunt them, the chameleon has developed new ways to make itself invisible. Most species live in trees; if they make themselves narrow they can 
hide behind a branch. If species that live on the ground see a predator, they disguise themselves as a leaf by contorting their body in such a way that they resemble crumpled leaves on the forest floor.

But there are some dangers the chameleon cannot escape, for example when the forest it lives in is burned down to make place for agriculture. According to the IUCN list, 9 species are 'critically endangered', 37 'endangered', 20 'vulnerable' and 35 'near endangered'.

Since 2006, Tolley has discovered eleven new chameleon species in South Africa, Mozambique, Tanzania and the Democratic Republic of the Congo. "If DNA research confirms that it is indeed a new species, you feel like you are not just writing a scientific article that no-one reads anyway", Tolley says. "Then you have achieved something that lasts."

But then she immediately says: "At the same time you think: wow, this is amazing, it strikes terror in me. Because I constantly imagine how those little chameleons clamp onto their branches while the forest around them is destroyed."

Hoarsely: "And then I wish we'd never found them. Because if this does not end, they will soon be extinct."

\section{Author's address}

Hannah N. M. De Mulder

Van Wijkplaats 4

2311 BX Leiden

The Netherlands

h.n.m.de.mulder@hum.leidenuniv.nl

\section{Biographical notes}

Hannah De Mulder is now at LUCL, Leiden University, The Netherlands 